Research Article

\title{
Periodic Cycles of Eyewall Convection Limit the Rapid Intensification of Typhoon Hato (2017)
}

\author{
Rong Fang $\mathbb{D}^{1},{ }^{1}$ Shumin Chen $\mathbb{D}^{1},{ }^{1}$ Mingsen Zhou, ${ }^{2}$ Weibiao Li, ${ }^{1}$ Hui Xiao, ${ }^{2}$ Tang Zhan, ${ }^{3}$ \\ Yusi Wu, ${ }^{1}$ Haoya Liu, ${ }^{1}$ and Chaoyong $\mathrm{Tu}^{1}$ \\ ${ }^{1}$ School of Atmospheric Sciences, Guangdong Province Key Laboratory for Climate Change and Natural Disaster Studies, \\ Sun Yat-sen University, Guangzhou 510275, China \\ ${ }^{2}$ Guangzhou Institute of Tropical and Marine Meteorology, China Meteorological Administration, Guangzhou 510062, China \\ ${ }^{3}$ China Zhuhai National Climate Observatory, Zhuhai 519000, China
}

Correspondence should be addressed to Shumin Chen; es04csm@mail2.sysu.edu.cn

Received 6 January 2021; Revised 3 May 2021; Accepted 19 May 2021; Published 30 May 2021

Academic Editor: Tomeu Rigo

Copyright (C) 2021 Rong Fang et al. This is an open access article distributed under the Creative Commons Attribution License, which permits unrestricted use, distribution, and reproduction in any medium, provided the original work is properly cited.

\begin{abstract}
The ability to forecast tropical cyclone (TC) intensity has improved modestly in recent years, partly because of an inadequate understanding of eyewall convection processes. Short-term periodic convection activities (period: $3-5 \mathrm{~h}$ ) have been identified in a number of TCs, but the effect of these activities on the evolution of TC intensity at the hourly scale is yet to be fully investigated. Using radar observations and a high-resolution numerical simulation based on the Weather Research and Forecasting model, we analyzed the periodic cycles of eyewall convection associated with the intensification of Typhoon Hato (2017). Results indicate the presence of four short-term periodic cycles (period: $3-5 \mathrm{~h}$ ) in the eyewall convection, which correspond to TC intensification. We further divided each cycle into three stages. The periodic evolution of convection inhibited the rapid intensification of the TC. The highest and lowest intensification rates were associated with the first and third stages according to the virtual potential temperature tendency in the eyewall region, respectively. Heating was dominated by the vertical advection associated with sensible heat and latent heat, which were controlled by the eyewall convection and structure. Of the three stages in each cycle, the vertical transport released the largest amount of latent heat in the first stage; consequently, the highest intensification rate occurred in this stage. In the second stage, heating was reduced because of decreased latent heat and increased cooling of sensible heat associated with vertical advection as the eyewall intensified. Vertical transport was the weakest in the third stage; this resulted in the smallest amount of heating, which limited the rapid intensification of the TC.
\end{abstract}

\section{Introduction}

Tropical cyclones (TCs), which develop over warm tropical oceans, are among the most destructive natural phenomena. However, the ability to forecast TC intensity has improved modestly in recent years [1-3]. A TC is a complex system. Its intensity is affected by various external and internal factors that interact on different scales [4-6]. Inadequate understanding of the internal processes of a TC, possibly because of the lack of high-precision observational data, is one of the main factors limiting the ability to predict TC intensity $[7,8]$.

Many studies have found that the eyewall is the main region affecting TC intensity $[9,10]$ and that heating in the eyewall area contributes very effectively to TC intensification. This is because inertial stability is at its maximum in the eyewall area, and the efficiency of the generation of kinetic energy from the injected heat energy increases with increasing inertial stability. This has been demonstrated by theoretical calculations and is consistent with observations [11-15]. The eyewall comprises numerous towering convective systems encircling the TC eye, which are responsible for the severest weather, including the strongest winds $[16,17]$. In particular, severe convection (also known as hot towers) around the eyewall plays an important role in TC intensification $[18,19]$. Within the radius of maximum wind (RMW), numerous hot towers in the downshear wind 
direction can indicate the potential for rapid TC intensification. This phenomenon has been identified and reproduced in a number of observational and simulation studies $[20,21]$. Idealized experiments show that the ambient wind shear also controls TC intensity by affecting the hot towers through advection of cold air into the core region in the middle layer [22-24].

With the exception of the eyewall replacement cycle and semidiurnal convection $[25,26]$, the periodic activities of eyewall convection that affect TC intensity are mostly related to vortex Rossby waves (VRWs) [27-31]. Kuo et al. [32] applied Lord Kelvin's linear analysis of the cyclonic rotation of asymmetric perturbations in the polygonal eyewalls by VRWs to Typhoon Herb (1996). Following this analysis, wave phase speed is given by $c=V_{\max }(1-1 / m)$, where $c$ is the wave phase speed, $V_{\max }$ is the vortex maximum wind, and $m$ is the azimuthal wavenumber; the rotation period decreases as the tangential wavenumber increases. In Typhoon Herb, the elliptical eyewall rotated with a period of $144 \mathrm{~min}$, along with wavenumber-2 (WN2) deep convection at the edge of the major axis [32]. A similar analysis of Hurricane Olivia (1994) showed an elliptical TC vortex rotating with wavenumber-1 deep convection in the presence of strong vertical wind shear [33]. Kuo et al. [34] demonstrated that the boundary layer (BL) radial inflow is also in control of the deep convection period. From radar observations of Typhoon Guillermo (1997), Reasor et al. [27] identified convective burst cycles with a period of $0.6-2 \mathrm{~h}$. Cycles began with the convective burst appearing in the downshear-left quadrant and ended with the cyclonic wrapping of upper-level updrafts into the downshear side of the eyewall.

Using both observational data and modeling results, Chen et al. [35] identified the short-term oscillations (period $=\sim 2-5 \mathrm{~h}$ ) in the vertical structure of the eyewall of Typhoon Hagupit (2008) and hypothesized that the oscillation of the inflow in the BL caused by air density oscillation could affect eyewall convection. These oscillations could cause fluctuations in TC intensity by controlling the heat transport near the warm core, which drives the lower-layer winds through the thermal wind balance [36-38]. Shortterm oscillations were also common in the simulation of 15 typhoons in the South China Sea (SCS) and the western North Pacific Ocean [39]. These oscillations are different from the VRWs because the circulation integral along the TC radials of any oscillation variable is oscillating and hence nonzero.

Periodicity is present in both eyewall structure and convection. A large number of hot towers may cause the rapid intensification (RI) of TCs. However, previous studies have left some issues unexplored. These include the shortterm changes (at the hourly scale) in TC intensification related to different stages in the evolution of eyewall convection and different processes that link the short-term oscillations in eyewall convection with TC intensification. Using radar observations and a numerical simulation of Typhoon Hato (2017), in this study, we analyzed the shortterm periodic cycles of eyewall convection and their influence on TC intensification. Typhoon Hato developed to the east of Luzon on 19 August 2017 and moved rapidly toward the west-northwest across the SCS. It rapidly intensified, as defined by an increase in the maximum surface wind speed of at least $15.4 \mathrm{~m} \mathrm{~s}^{-1}$ day $^{-1}$ [6], and struck the GuangdongHong Kong-Macao Greater Bay Area on 23 August as a Category 3-equivalent storm that caused 24 fatalities and damage totaling US\$6.82 billion. The name Hato was retired from the nomenclature of tropical cyclones in the western North Pacific and the SCS in 2018.

The remainder of this paper is organized as follows. Section 2 presents the radar observations of eyewall convection in the hours before Hato (2017) made landfall, the data and methods used in this study, and model configuration and validation. Section 3 includes an analysis of the evolution of the short-term periodic activities in eyewall convection in model results and diagnoses of their influence on TC intensity. We present our summary and conclusions in Section 4.

\section{Materials and Methods}

2.1. Periodic Cycles in Radar Observations. We analyzed radar composite reflectivity from the operational weather radar network in Guangdong Province and a concatenation of radar echo images from Zhuhai and Hong Kong to examine the evolution of the short-term periodic activities in eyewall convection. Nearly two complete cycles were identified during the $\sim 6 \mathrm{~h}$ period between 20:36 UTC on 22 and 02:24 UTC on 23 August 2017, before Hato made landfall. According to the besttrack databases from the Shanghai Typhoon Institute of the China Meteorological Administration (CMA) [40], Hato intensified rapidly during this period. Maximum wind speed increased by approximately $13 \mathrm{~m} \mathrm{~s}^{-1}$, and minimum sea level pressure (MSLP) decreased by approximately $20 \mathrm{hPa}$. In each cycle, weak convection in the eyewall intensified, reaching maximum intensity, and then gradually weakened again. The period of each cycle was approximately $3 \mathrm{~h}$.

Radar reflectivity images from the CMA of the first cycle are shown in Figures 1 and 2. At 20:36 UTC on 22 August 2017, maximum reflectivity at $3 \mathrm{~km}$ altitude in the eyewall was $>50 \mathrm{dBZ}$ and appeared on the northwestern side of the TC (Figure 1(a)). This severe convection rotated counterclockwise around the TC center and reached maximum intensity at 21:48 UTC when it reached the southern side of the TC. At this time, radar composite reflectivity at $18 \mathrm{dBZ}$ was above $20 \mathrm{~km}$ height (Figure 2(c)). The entire eyewall was filled gradually. The convective structure became relatively uniform, and radar reflectivity was not notably high in comparison with earlier stages (Figure 1(f)). At this point, the weakened eyewall was also about to rebuild for the next cycle. During the second cycle, the eyewall was stronger, but the evolution of the convection was similar to that of the first cycle (figure not shown). The second cycle began at 23:48 UTC on 22 August, ended at 02:24 UTC on 23 August 2017, and had a period of $\sim 3 \mathrm{~h}$.

\subsection{Simulation and Validation}

2.2.1. Model Configuration. Given that the radar observations could not capture eyewall convection when Hato was 


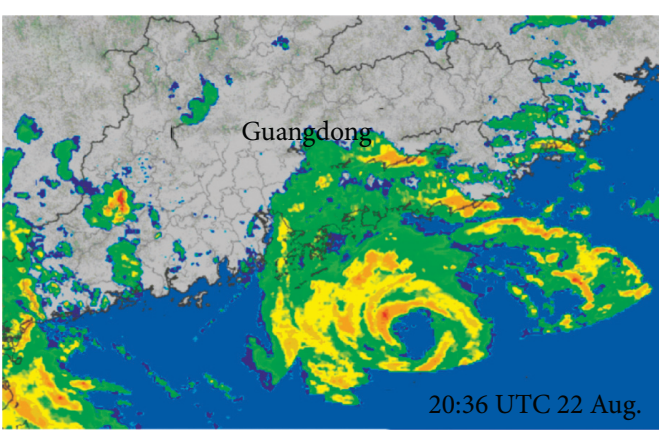

(a)

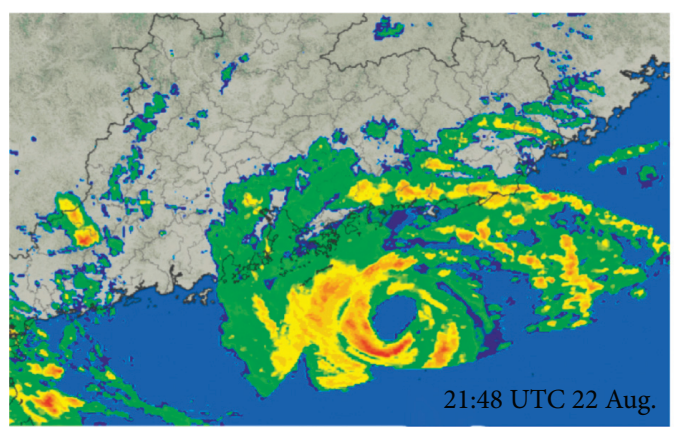

(c)

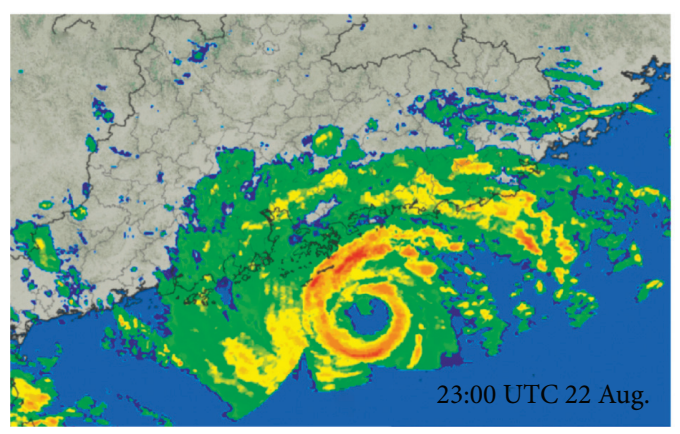

(e)
dBZ

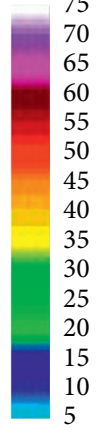

BZ

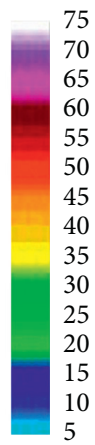

dBZ

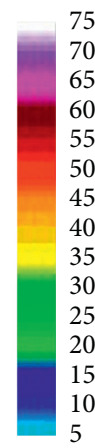

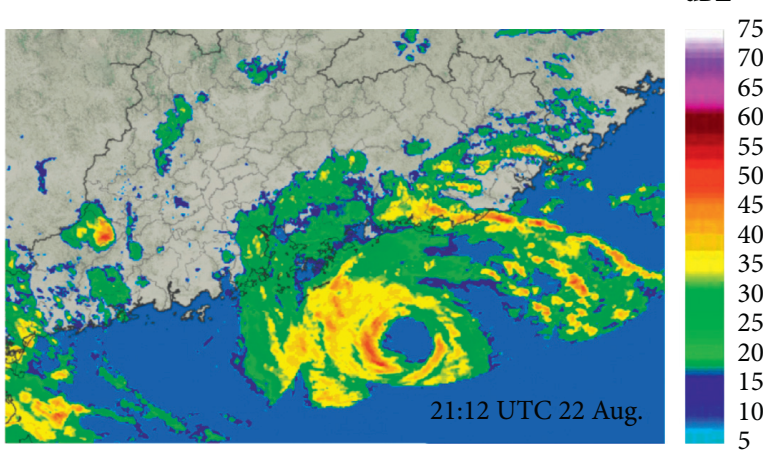

(b)

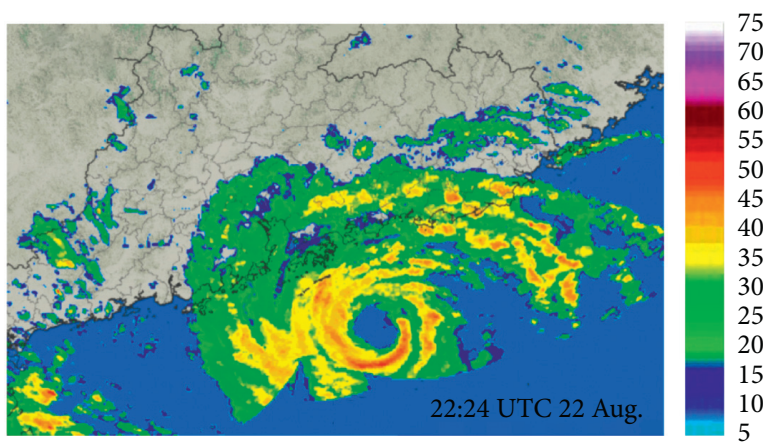

(d)

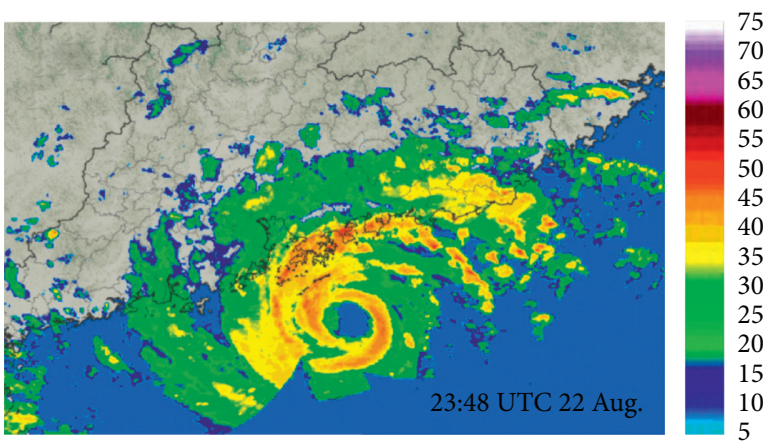

(f)

FIGURE 1: Radar composite reflectivity at $3 \mathrm{~km}$ altitude (unit: dBZ) from China Meteorological Administration (CMA) operational weather radars in Guangdong Province on 22 August 2017: (a) 20:36 UTC, (b) 21:12 UTC, (c) 21:48 UTC, (d) 22:24 UTC, (e) 23:00 UTC, and (f) 23: 48 UTC.

far from the southern coast of China, a numerical simulation was needed for the following analysis. We used the Advanced Research Weather Research and Forecasting model (WRF-ARW) version 3.8.1 to simulate Hato between 12:00 UTC on 21 August 2017 and 12:00 UTC on 23 August 2017. This is one of the models with the best performance in cyclone simulation $[5,18,41,42]$.

The initial and boundary fields of the simulation were both obtained from the initial fields of the medium-range forecasts produced by the Regional Specialized Meteorological Centre of the European Centre for Medium-Range Weather Forecasts. They have a horizontal resolution of $0.125^{\circ} \times 0.125^{\circ}, 18$ vertical layers, and time intervals of $6 \mathrm{~h}$.
The model was run using a two-way nested technique and the Mercator projection with a $5 \mathrm{~min}$ output interval. The low-resolution domain had $597 \times 375$ grids with a grid interval of $6 \mathrm{~km}$, and the high-resolution domain had $1236 \times 501$ grids with a grid interval of $2 \mathrm{~km}$ (Figure $3(\mathrm{a})$ ). The Rapid Radiative Transfer Model (RRTM) longwave radiation scheme [43], Dudhia shortwave radiation scheme [44], revised Monin-Obukhov scheme [45], Noah land surface scheme [46], Yonsei University (YSU) planetary BL scheme [47], and WRF single-moment 6-class microphysics [48] were adopted for both domains. The low-resolution domain used the Kain-Fritsch cumulus parameterization scheme [49-51], while no cumulus parameterization scheme 


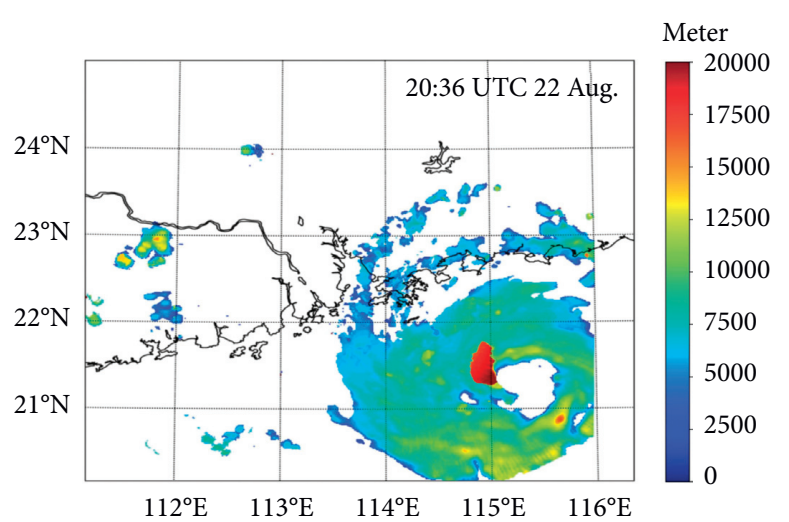

(a)

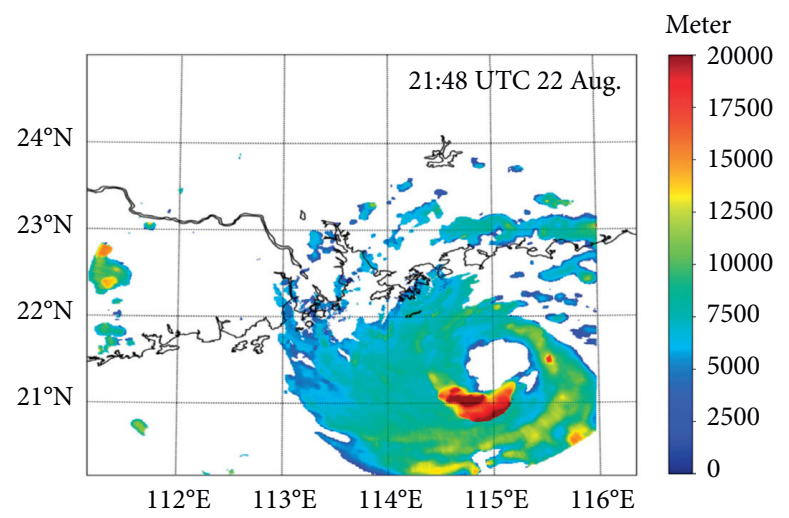

(c)

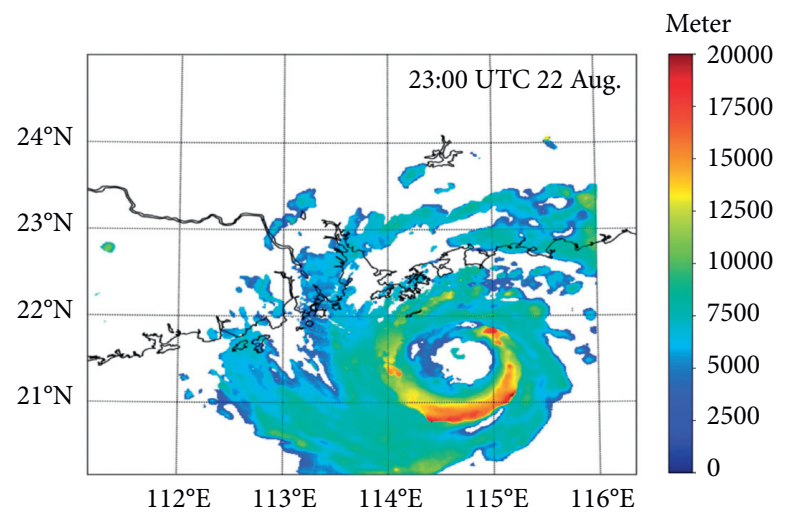

(e)

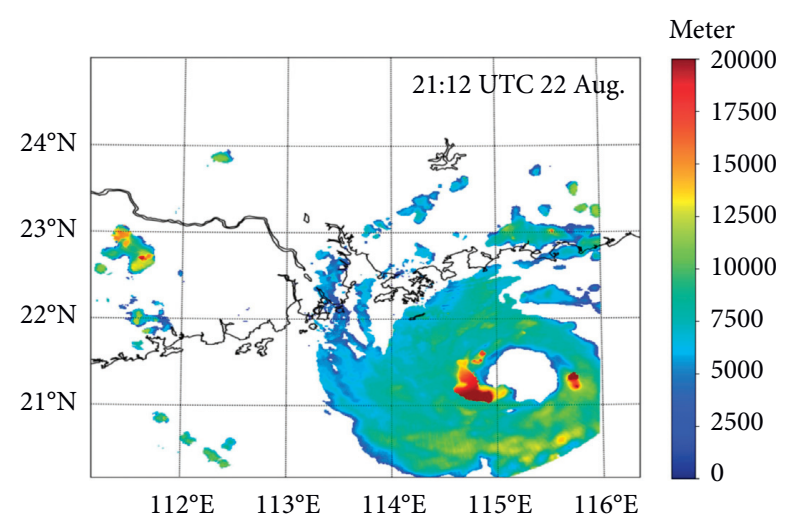

(b)

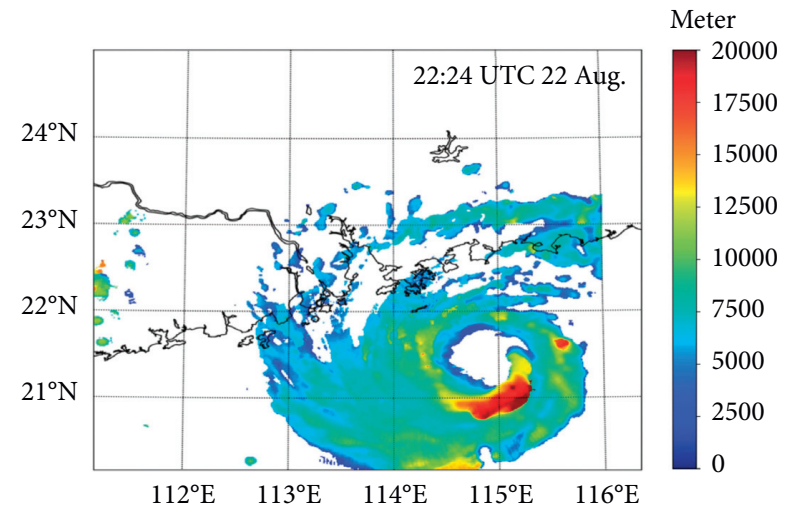

(d)

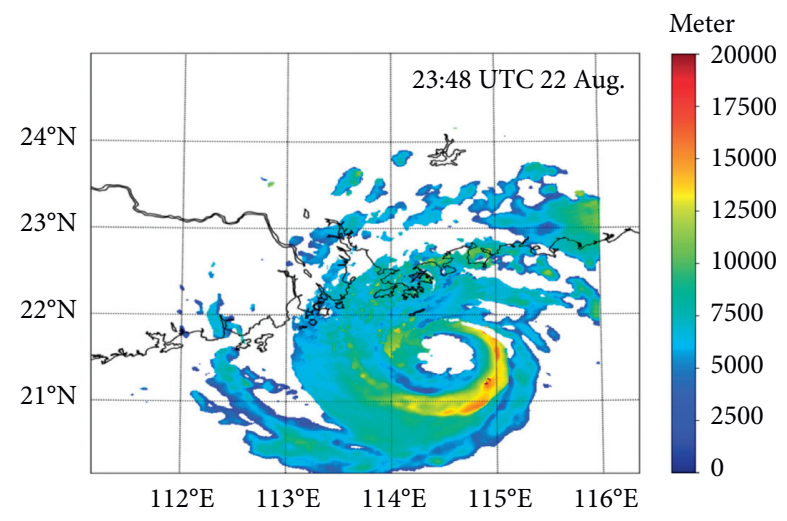

(f)

Figure 2: Peak height of radar composite reflectivity at $18 \mathrm{dBZ}$ from a concatenation of radar echo images from Zhuhai and Hong Kong of the CMA on 22 August 2017: (a) 20:36 UTC, (b) 21:12 UTC, (c) 21:48 UTC, (d) 22:24 UTC, (e) 23:00 UTC, and (f) 23:48 UTC.

was used for the high-resolution domain. Sigma coordinates were adopted. There were 30 vertical layers, and the top layer had a pressure of $50 \mathrm{hPa}$.

2.2.2. Model Validation. We compared WRF simulation results of Hato with observations from three best-track databases; these included the 1, 10, and 2 min maximum sustained $10 \mathrm{~m}$ wind speeds from the Joint Typhoon Warning Centre (JTWC), Japan Meteorological Agency (JMA), and CMA, respectively [40]. The model successfully reproduced both the track and the variations in intensity
(Figure 3). Variations in simulated intensity were generally consistent with those in the observations. However, the initial stage of the simulation was relatively unstable, and the simulated intensity was slightly higher than the observed intensity, especially at the beginning of the simulation, because of the high horizontal resolution of the initial field used in the simulation and the strong initial vortex. The instability during the initial stage is further discussed later. In addition, the difference between simulated and observed intensities could also be attributed to different averaging times of the maximum sustained $10 \mathrm{~m}$ wind speeds in the three databases. In the model, the wind-pressure 


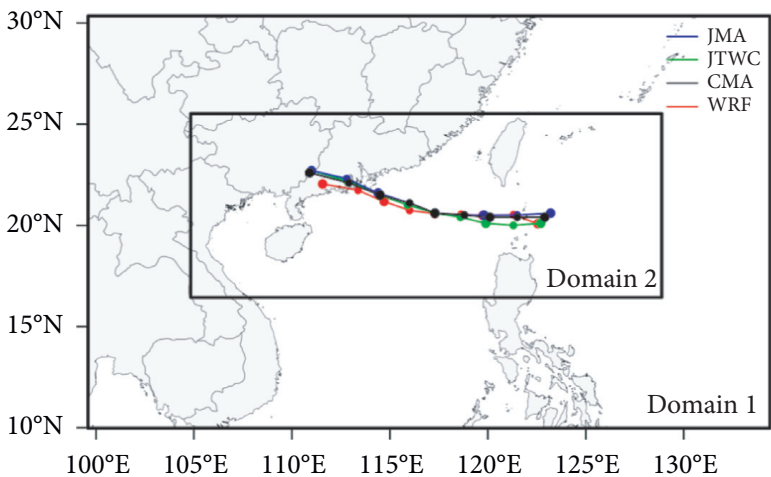

(a)

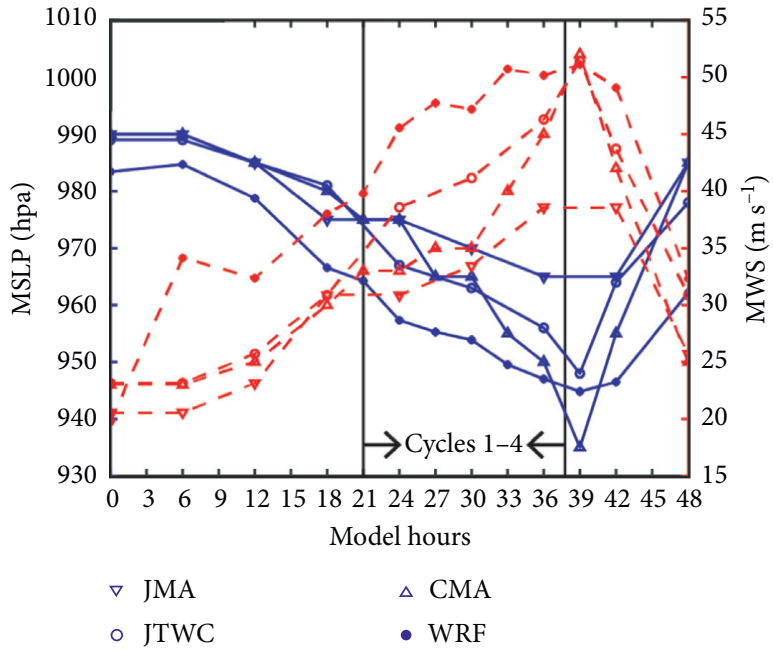

(b)

Figure 3: Model domains and Hato $6 \mathrm{~h}$ tracks and intensities from observations and simulations between 12:00 UTC on 21 August 2017 and 12:00 UTC on 23 August 2017 (model hours 0-48). (a) Location of the domains and track observations from the Japan Meteorological Agency (JMA; blue), Joint Typhoon Warning Centre (JTWC; green), China Meteorological Administration (CMA; black), and WRF simulated track (red). (b) Minimum sea level pressure (MSLP; blue lines) and maximum $10 \mathrm{~m}$ wind speed (MWS; red lines) from best-track databases, and the WRF simulation between the black solid lines is the analysis time from cycles 1 to 4 .

relationship is approximated by a basic system of equations describing atmospheric motion. However, observations from the best-track databases reflect additional disturbances in the atmosphere that are not represented by the equations and should therefore be further examined in future studies. Hato reached its maximum intensity of $\sim 946 \mathrm{hPa}$ with $10 \mathrm{~m}$ wind speeds of $\sim 52 \mathrm{~m} \mathrm{~s}^{-1}$ at model hour 39 (Figure 3(b)), which was $2 \mathrm{~h}$ before it made landfall in Zhuhai in the WRF simulation and approximately the time of landing according to the best-track databases (Figure 3(a)). To examine the data at subday intervals, we defined the threshold of RI as $-10.5 \mathrm{hPa}$ for the sea level central pressure or $3.85 \mathrm{~m} \mathrm{~s}^{-1}$ for the maximum surface wind speed per $6 \mathrm{~h}$, following the definitions of Holliday and Thompson [52] and Leroux et al. [6]. Simulated TC intensity increased from $39.6 \mathrm{~m} \mathrm{~s}^{-1}$ at hour 21 to $51.7 \mathrm{~m} \mathrm{~s}^{-1}$ at hour 39, which indicated that Hato had undergone a process of RI. A similar trend was found in the JTWC data, although simulated values exceeded values obtained from the three best-track databases.

Before model hour 21, RMW at the height of $3 \mathrm{~km}$ $\left(\mathrm{RMW}_{3}\right)$ and the tilt of the TC center between the sea level and the height of $6.6 \mathrm{~km}$ were contracting dramatically (Figure 4). To examine the periodic changes of TC intensity and eyewall characteristics before TC landfall at a time of stable TC evolution, we focused on the results from model hours 21-39 (the analyzed period) when the simulated TC was rapidly intensifying. We defined a radius of $20-80 \mathrm{~km}$, which was $0.75-1.5 \mathrm{RMW}_{3}$ [17], as the eyewall region. The centroid at the sea level was adopted as the TC center so that small-scale disturbances could be filtered out to make the center more representative of the TC location. Following Kanada and Wada [53], for each node that was within $60 \mathrm{~km}$ of the node with the lowest pressure in the $2 \mathrm{~km}$ mesh, we calculated the pressure accumulated over a radius of $100 \mathrm{~km}$.

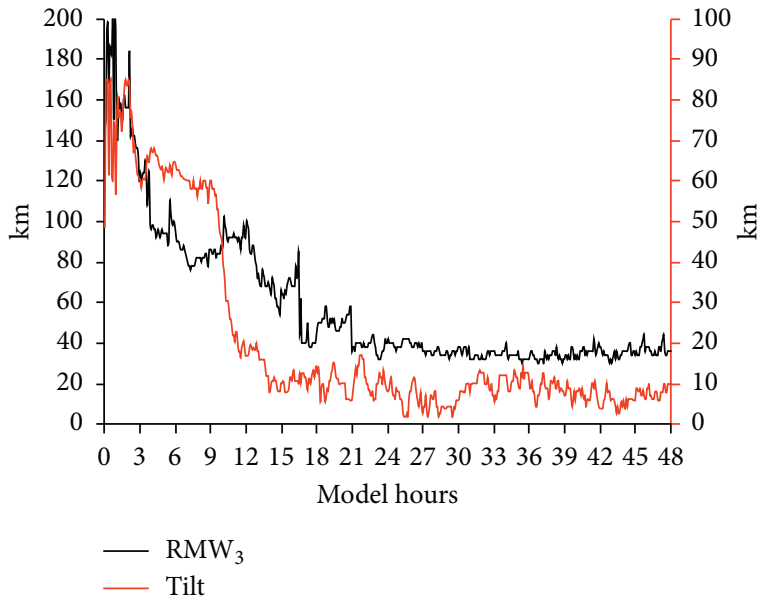

FIGURE 4: RMW (black line) at the height of $3 \mathrm{~km}$ and the tilt of the TC center between the sea level and the height of $6.6 \mathrm{~km}$ (red line) in the simulation.

The centroid was defined as the node with the lowest accumulated pressure.

Because of the difference between the simulated and observed landing time, the periodic cycles of eyewall convection in the simulation lead those in the observations by $2 \mathrm{~h}$. Comparisons of Figures 5 and 6 and 1 and 2 show that the changes of the eyewall structure were well simulated, except that the maximum cloud top height in Figure 5(c) was $18.5 \mathrm{~km}$, which was lower than that in Figure 2(c). Notably, the frontal rainfall structure on the continent ahead of the travelling TC was not well simulated by the model, and the interaction between this frontal rainfall and the TC eyewall should be analyzed in detail in a future study. 
$\mathrm{dBZ}$

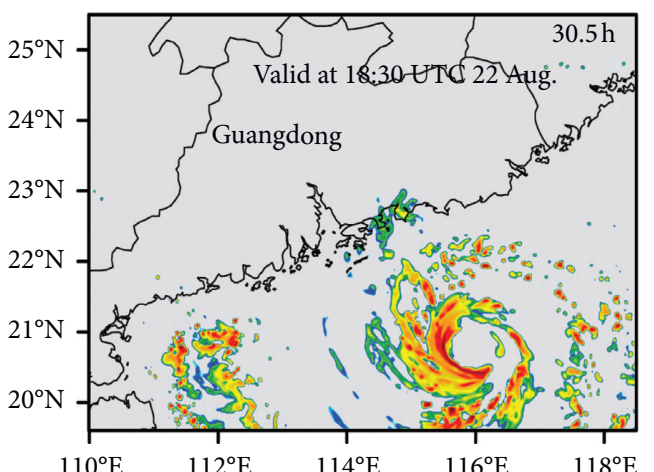

(a)

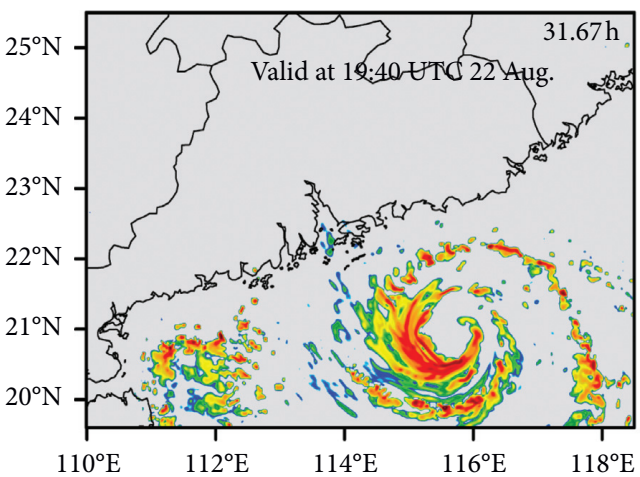

(c)

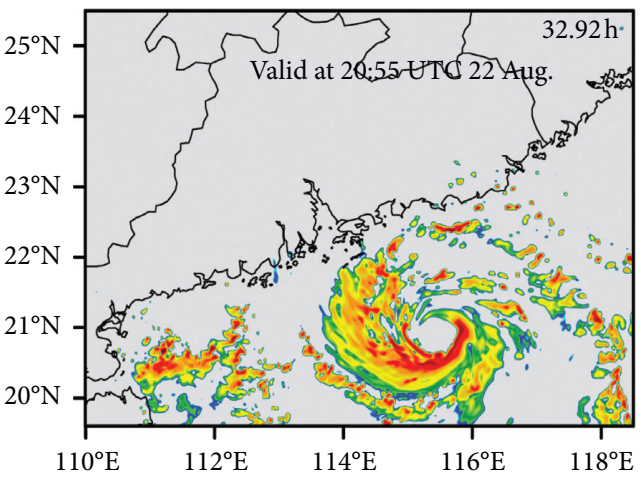

(e)

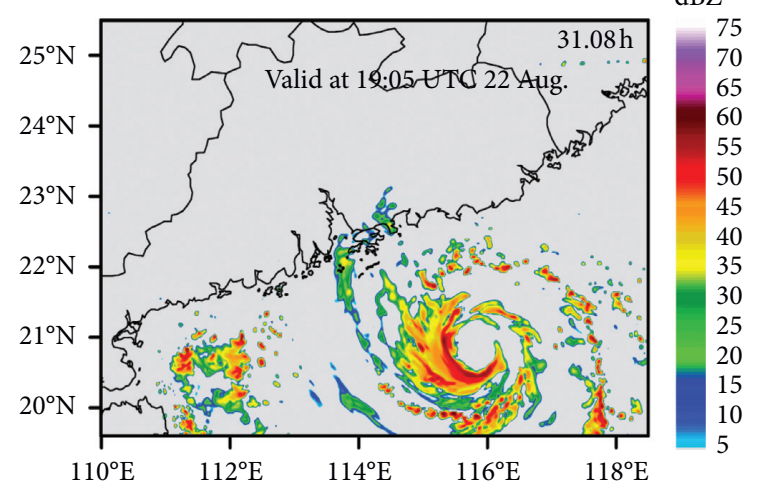

(b)

$\mathrm{dBZ}$
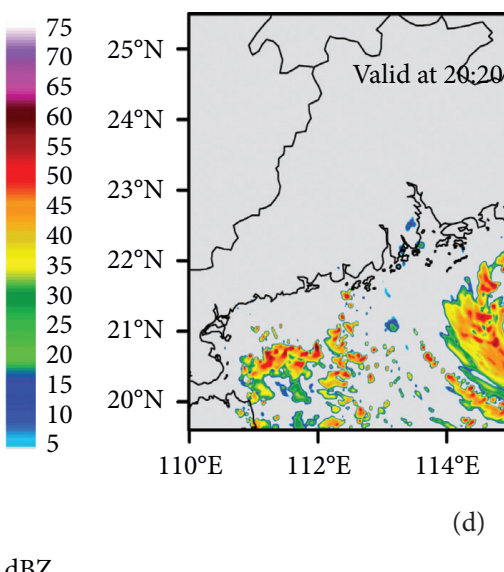

dBZ

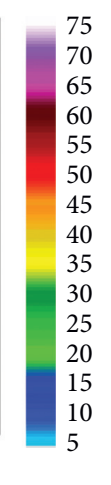$$
24
$$

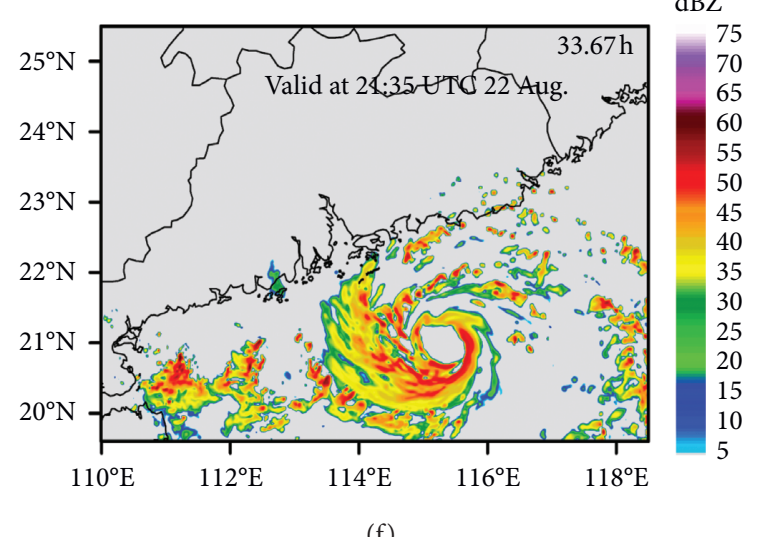

FIGURE 5: Reflectivity at $3 \mathrm{~km}$ altitude (unit: dBZ) derived from the WRF simulation at model hours (a) 30.5 , (b) 31.08 , (c) 31.67 , (d) 32.33 , (e) 32.92 , and (f) 33.67 .

Figure 7 shows the evolution of the average radar reflectivity in the eyewall at $3 \mathrm{~km}$ altitude with azimuth in the observation data and model results. Observation data with an approximately $6 \mathrm{~h}$ period show high radar reflectivity on the western side of the TC and two periodic cycles that extend from northwest to southwest. The counterclockwise motion and the two periodic cycles were reproduced in the WRF simulation, although simulated average radar reflectivity was approximately $4 \mathrm{dBZ}$ higher than the observed reflectivity, and were shifted more southward. In summary, the model reproduced the TC track, variations in intensity, and the periodic cycles of eyewall convection at a reasonably satisfactory level. Given the lack of high-precision observational data, we consider that the simulation results are adequate for further analysis of the short-term oscillations of eyewall convection and their effects on TC intensification.

\section{Results and Discussion}

3.1. RI of the TC Was Limited by Periodic Eyewall Cycles. For model hours 21-39, we analyzed the coupled oscillations of two sequences using a cross-wavelet transform [54]: 


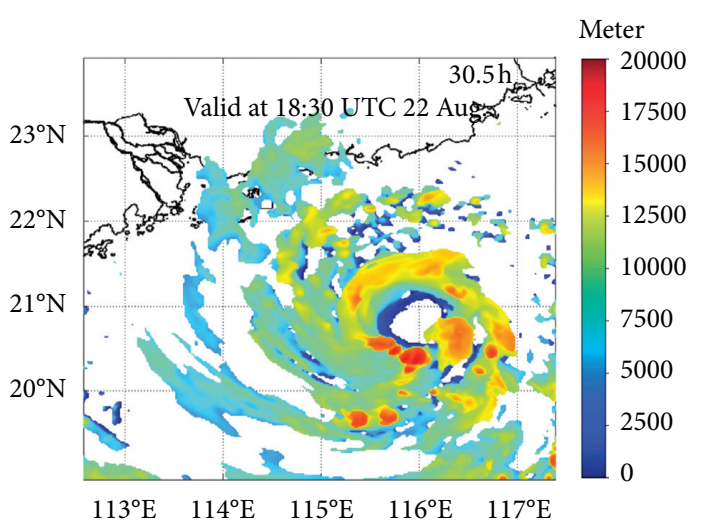

(a)

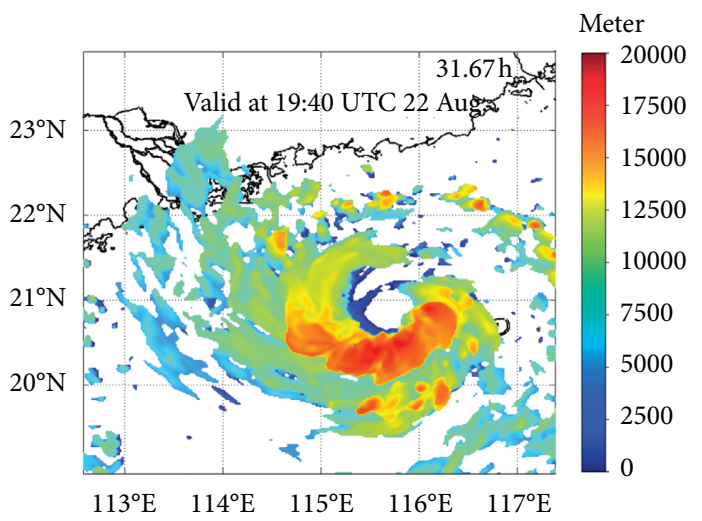

(c)

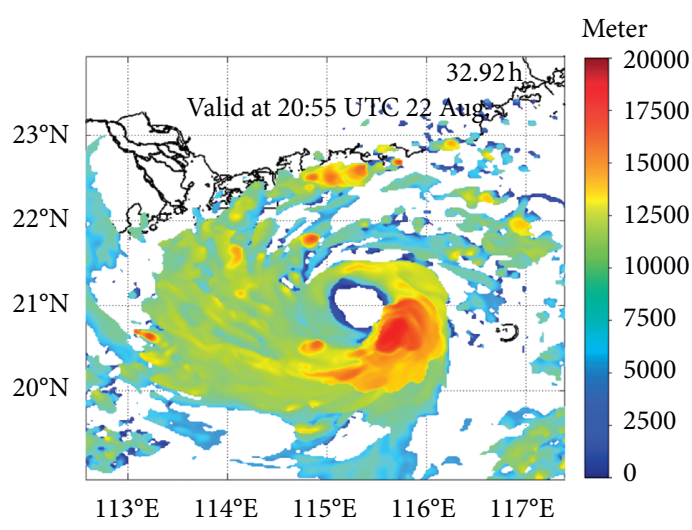

(e)

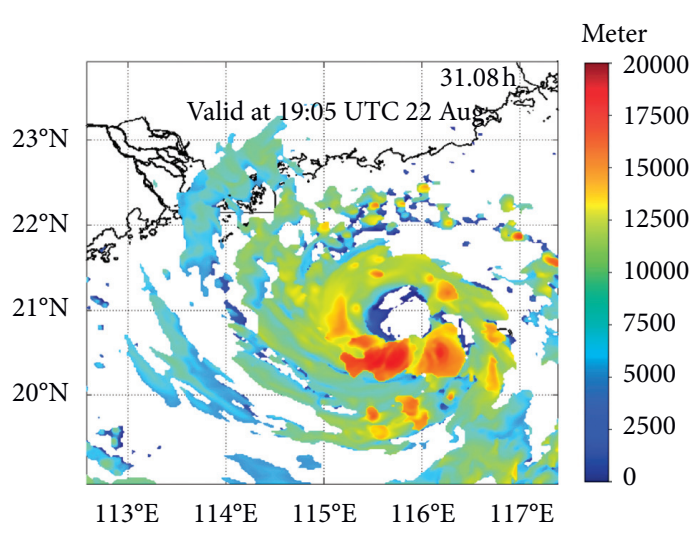

(b)

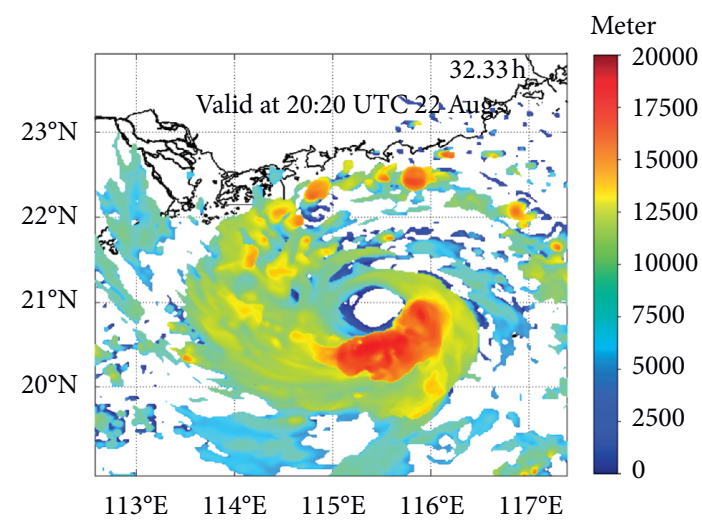

(d)

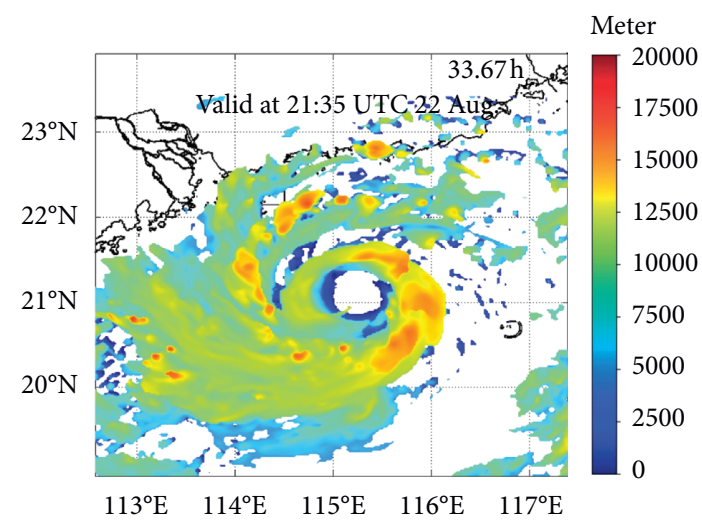

(f)

FIGURE 6: Peak height of radar composite reflectivity at $18 \mathrm{dBZ}$ derived from the WRF simulation at model hours (a) 30.5 , (b) 31.08 , (c) 31.67 , (d) 32.33 , (e) 32.92, and (f) 33.67 .

$$
W_{f, g}(s, \tau)=\overline{W_{f}(s, \tau)} W_{g}(s, \tau),
$$

where $f$ presents the intensification rate (IR) of the TC, which is measured by the change in minimum sea level pressure ( $\triangle \mathrm{MSLP}), g$ represents the convection strength, which is measured by the average vertical speed of updrafts at $200 \mathrm{hPa}$ within the eyewall region, $W(s, \tau)$ is the continuous wavelet transform using the Morlet mother wavelet, crossbar represents the complex conjugation, and $\overline{W_{f}(s, \tau)} W_{g}(s, \tau)$ represents the time-scale decomposition of the covariance of the two signals $f$ and $g$. Results indicate the presence of a coupled IR- high-level convection oscillation with a period of $\sim 3-5 h$ (Figure 8). There was also another oscillation with a period of 1 $2 \mathrm{~h}$, which might be related to the lifetime of the hot towers; the discussion of this phenomenon lies beyond the scope of this study. The correlation coefficient between the 3-5 $\mathrm{h}$ bandpassfiltered IR and the average vertical velocity of updrafts at $200 \mathrm{hPa}$ was -0.66 , which was statistically significant at the $90 \%$ confidence level. Moreover, as the TC approached the land after model hour 34, the period became slightly shorter, which was consistent with the conclusion that BL convergence promotes high-frequency oscillation in typhoons [39]. 


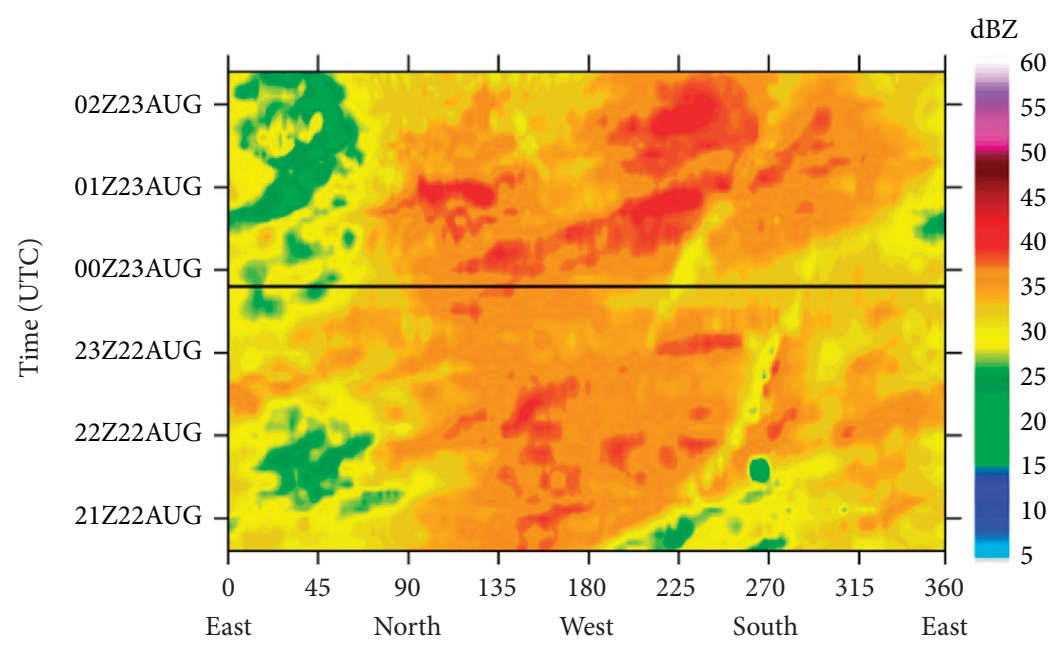

(a)

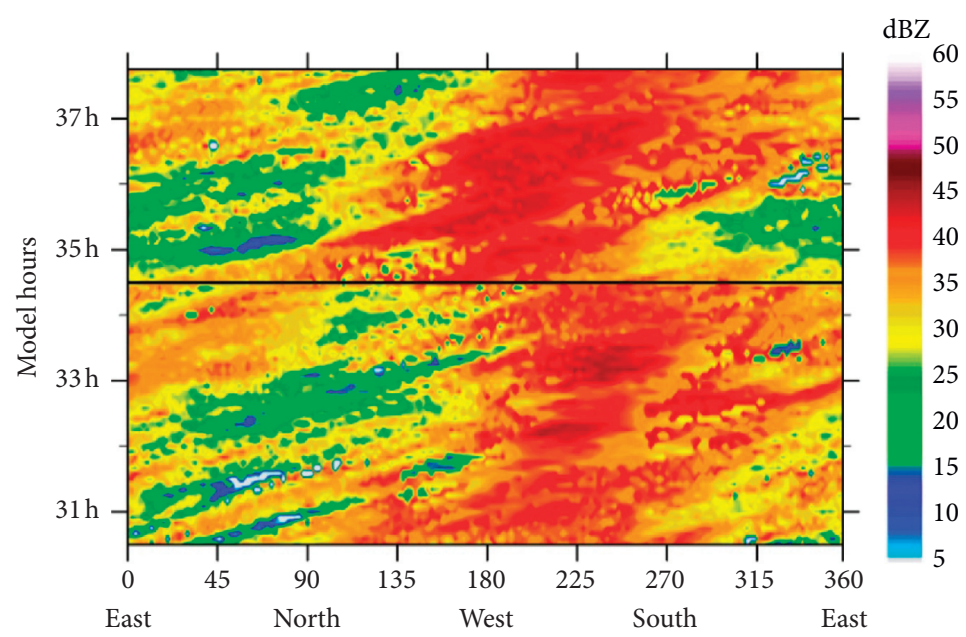

(b)

Figure 7: Variation of the average radar reflectivity in the eyewall (radius of 20-80 km) at $3 \mathrm{~km}$ altitude with time and azimuth in (a) radar observations and (b) WRF simulation. In (a) and (b), the horizontal black line marks the division between two cycles.

Under the 3-5 h common power results of the evolution of the cross-wavelet transform, we classified four cycles and three stages in each cycle based on the IR tendency of the TC from the simulation results (Figure 9). To avoid a disturbance in the MSLP and maximum wind speed, the IR is represented by two more stable variables, the hourly change in the sea level pressure at the TC center averaged within a radius of $20 \mathrm{~km}$ and the maximum tangential wind (Figure 9(a)). The tangential wind was derived from the difference between the result of the decomposition of the simulated speed and the average moving velocity of the whole TC. The average moving velocity was calculated by dividing the volume integral of the simulated speed over the heights of $1-14 \mathrm{~km}$ and radius of $200 \mathrm{~km}$ by the volume of the region [55]. Of the four cycles that are present in the simulation, only the last two are present in the radar observation data; the first two cycles are absent from the observations as the TC was too far from the continent (figures not shown). During these cycles, although Hato experienced RI, the IR was limited by the periodic cycles. In each cycle, three stages were included, and the IR of these stages decreased with time
(Figure 9(c)): rapid intensification (with a mean IR of $\leq-1.5 \mathrm{hPah}^{-1}$ in pressure or $\geq 2 \mathrm{~m} \mathrm{~s}^{-1} \mathrm{~h}^{-1}$ in wind speed, accompanied by the rapid intensification of the eyewall convection); medium slow intensification (with $-1.5 \mathrm{hPah}^{-1}<\mathrm{IR}<-0.4 \mathrm{hPah}^{-1}$ in pressure or $0 \mathrm{~m} \mathrm{~s}^{-1} \mathrm{~h}^{-1}<\mathrm{IR}<2 \mathrm{~m} \mathrm{~s}^{-1} \mathrm{~h}^{-1}$ in wind speed, accompanied by convection developing to a peak and changing relatively slowly); and slow intensification or weakening (with IR of $\geq-0.4 \mathrm{hPah}^{-1}$ in pressure or $<0 \mathrm{~m} \mathrm{~s}^{-1} \mathrm{~h}^{-1}$ in wind speed, accompanied by the weakening of the eyewall convection). Taking the third cycle as an example, the IR of stages 1, 2, and 3 was approximately $-1.50,-0.67$, and $-0.25 \mathrm{hPa} \mathrm{h}^{-1}$, respectively. The analyses that follow, including convection, mass flux, latent heating, and sensible heating, were mostly based on this classification.

Mass fluxes of the periodic cycles of the updrafts and downdrafts could represent both the strength and the area of the convection. Mass fluxes at three model levels, 1.3, 5.6, and $12.7 \mathrm{~km}$ (approximately 850, 500, and $200 \mathrm{hPa}$ ), are shown in Figure 10. Between hours 21 and 39 and at all 


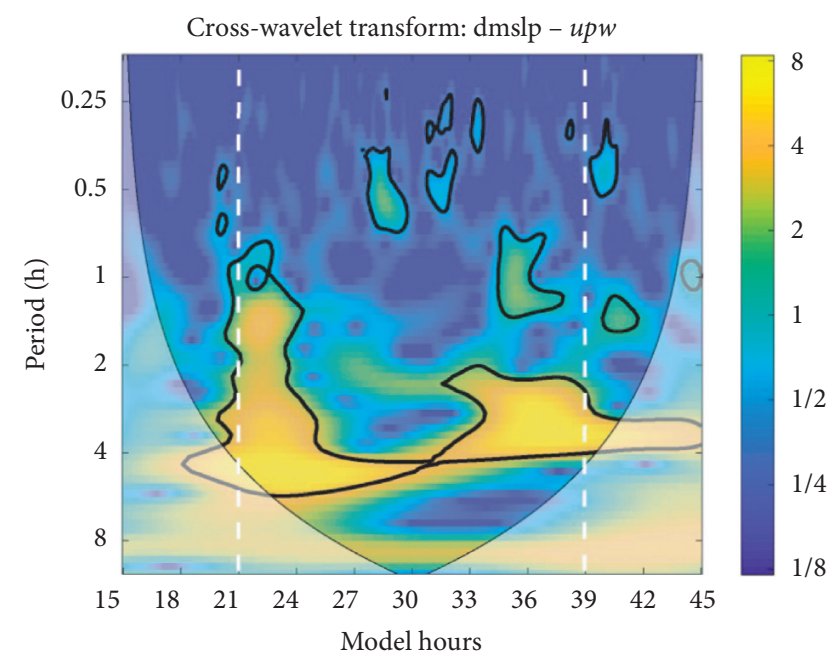

FIGURe 8: Power spectrum of the cross-wavelet transform of the standardized $\triangle$ MSLP and eyewall averaged updraft at $200 \mathrm{hPa}$ (equation (1)). The $90 \%$ significance level against red noise is shown as a thick contour, and the cone of influence, where edge effects might distort the picture, is shown as a lighter shade. The analyzed period is between the two white dotted lines.

levels, the convection had an asymmetrical azimuthal distribution. For example, the upward mass fluxes concentrated mainly on the southern side, and the large mass fluxes moved counterclockwise over time, especially at the middle and upper levels (Figures 10(a), 10(c), and 10(e)). At higher levels, the angle at which the strongest updrafts occurred changed to match with the direction of the downwind. In the case where TC intensification was accompanied by a clear long-term increase in the averaged vertical wind of the rising branch in the lower layers (figure not shown), convection in the upper layers exhibited clear cycles with a period of 3-5 h (Figures 10(e) and 10(f)), which is consistent with the results from the cross-wavelet transform. Maximum wind speed and the average pressure within the eye (at a radius of $0-20 \mathrm{~km}$ ) also fluctuated periodically, which indicates periodicity in TC intensity and the close relationship between TC intensification and the evolution of eyewall convection. Even if external factors (such as large-scale circulation and environmental wind shear) were relatively stable (figures not shown), TC intensity could not increase continuously at a steady rate. Instead, just like the convection, there was a buffer period that was relatively stable.
Rotation of the downward flux was less clear than that of the upward flux (Figures 10(b), 10(d), and 10(f)). Downward mass fluxes concentrated mainly on the eastern side in the lower and middle layers. This could be because that downward mass fluxes are mainly caused by the compensated subsidence of the heat towers in the upper layers and that subsidence is caused mainly by ambient wind shear in the middle and lower layers, which is concentrated mainly on the eastern side (figures not shown) [56]. The downward flux at the highest level in cycles 3 and 4 was smaller than the others in Figure 10(f). This might be related to variations in the tropopause divergence during the TC life cycle, although this should be confirmed in a future study.

Taking the 95th percentile of the vertical velocity of updrafts at $12.7 \mathrm{~km}$ as the threshold of strong convection [18], Figure 11 shows the total mass fluxes and the mass fluxes as a result of strong convection (vertical velocity $w>7.4 \mathrm{~m} \mathrm{~s}^{-1}$ ) for each of the stages of the four cycles. Periodicity was the most pronounced at the $12.7 \mathrm{~km}$ height. Therefore, we analyzed mass fluxes at this height in connection with the IR of the TC. For each cycle, stage 3 always had the lowest total mass flux, corresponding to the minimum IR. For the first, third, and fourth cycles, stage 3 also had the lowest mass flux from strong convection $\left(<0.34 \times 10^{10} \mathrm{~kg} \mathrm{~s}^{-1}\right)$. For the first, second, and fourth cycles, stage 2 had the highest total mass flux $\left(>1.35 \times 10^{10} \mathrm{~kg} \mathrm{~s}^{-1}\right)$ and highest mass flux from strong convection $\left(0.41 \times 10^{10} \mathrm{~kg} \mathrm{~s}^{-1}\right)$. There was no correspondence between the maximum IR in stage 1 and the strength of total convection or strong convection, which indicates that the IR of Hato had some connection with but was not fully related to the strength of the convection in the eyewall region. This finding is further discussed in Section 3.2.

3.2. Thermodynamic Analysis of TC Intensification. The correlation coefficient between model output and surface central pressure derived from virtual temperature was 0.9. The virtual potential temperature $\left(\theta_{v}\right)$ within a radius of $80 \mathrm{~km}$ clearly showed characteristics of periods and stages that were consistent with those of the IR (figure not shown). Therefore, to examine the thermodynamic processes underlying the physical relationship between the periodic convection cycles and TC intensification, we derived $\theta_{v}$ using the following diagnosis equation in cylindrical coordinates:

$$
\frac{\partial \theta_{v}}{\partial t}=-\left(u \frac{\partial \theta_{v}}{r \partial \varphi}+v \frac{\partial \theta_{v}}{\partial r}\right)-w \frac{\partial \theta_{v}}{\partial z}-\frac{\theta_{v} L_{v, s, f}}{C_{p d} T_{v}} \cdot\left[\left(u \frac{\partial q}{r \partial \varphi}+v \frac{\partial q}{\partial r}\right)+w \frac{\partial q}{\partial z}+\frac{\partial q}{\partial t}\right]+\text { residual }
$$

where $u$ and $v$ are the tangential and radial winds, respectively, $T_{v}$ is the virtual temperature, $C_{p d}$ is the specific heat at constant pressure, $L_{v, s, f}$ is the latent heat $(\mathrm{LH})$ of vaporization $(v)$ or sublimation $(s)$ or fusion $(f)$, and $q$ is the mixing ratio of different forms of water; the liquid forms of water include cloud water and rain water, and the solid forms include ice and graupel; $-(u \cdot \partial \theta v / r \partial \varphi+v \cdot \partial \theta v / \partial r)-w \cdot \partial \theta v / \partial z$ represents the sensible heating from tangential advection $(-u \cdot \partial \theta v / r \partial \varphi)$, radial advection $(-v \cdot \partial \theta v / \partial r)$, and vertical advection $(-w \cdot \partial \theta v / \partial z)$ of $\theta_{v} ;-\left(\theta_{v} L_{v, s, f}\right) /\left(C_{p d} T_{v}\right) \cdot[(u \cdot \partial q / r \partial \varphi)+v \cdot \partial q /$ $\partial r+w \cdot \partial q / \partial z]$ represents the latent heating from tangential advection $\left(-\left(\theta_{v} L_{v, s, f}\right) /\left(C_{p d} T_{v}\right) \cdot(u \partial q / r \partial \varphi)\right)$, radial advection 


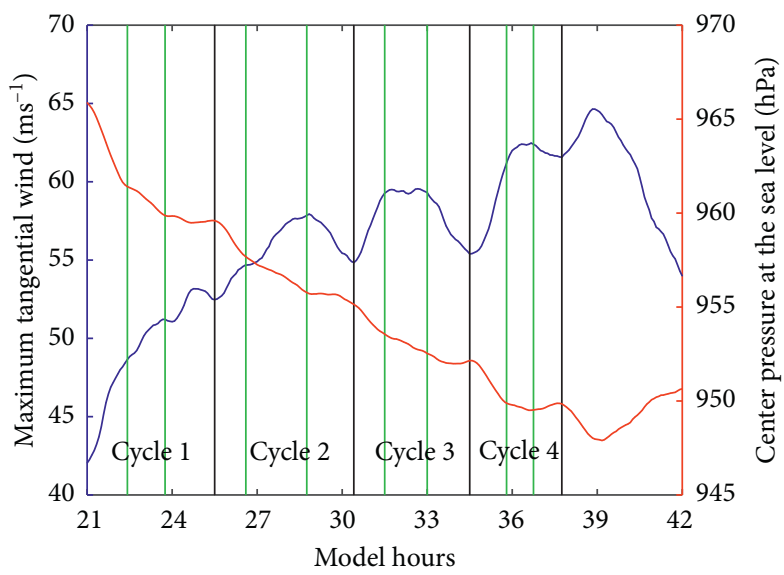

(a)

\begin{tabular}{lcccc}
\hline & Cycle 1 & Cycle 2 & Cycle 3 & Cycle 4 \\
\hline Stage 1 & $21.00-22.50 \mathrm{~h}$ & $25.50-26.50 \mathrm{~h}$ & $30.50-31.50 \mathrm{~h}$ & $34.50-35.75 \mathrm{~h}$ \\
Stage 2 & $22.50-23.75 \mathrm{~h}$ & $26.50-28.75 \mathrm{~h}$ & $31.50-33.00 \mathrm{~h}$ & $35.75-36.75 \mathrm{~h}$ \\
& & & & \\
Stage 3 & $23.75-25.50 \mathrm{~h}$ & $28.75-30.50 \mathrm{~h}$ & $33.00-34.50 \mathrm{~h}$ & $36.75-37.75 \mathrm{~h}$ \\
\hline
\end{tabular}

(b)

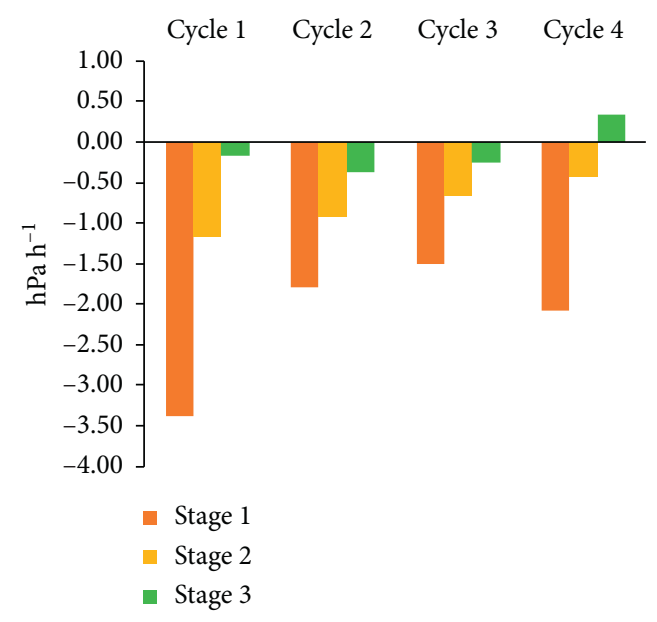

(c)

FiguRE 9: (a) TC intensity as represented by $1 \mathrm{~h}$ smoothed maximum tangential wind (unit: $\mathrm{m} \mathrm{s}^{-1}$; black line) and average pressure within the eye (radius of $0-20 \mathrm{~km}$ ) (unit: hPa; red line). The black lines identify different cycles, and the green lines identify different stages. (b) Table showing timing of the stages. (c) Graph showing IR values.

$\left(-\left(\theta_{v} L_{v, s, f}\right) /\left(C_{p d} T_{v}\right) \cdot(v \cdot \partial q / \partial r)\right)$, and vertical advection $\left(-\left(\theta_{v} L_{v, s, f}\right) /\left(C_{p d} T_{v}\right) \cdot(w \cdot \partial q / \partial z)\right)$ of $q ;-\left(\theta_{v} L_{v, s, f}\right) /\left(C_{p d} T_{v}\right) \cdot(\partial q /$ $\partial t$ ) represents the latent heating from the tendency of local $q$. The residual mainly includes nonlinear terms such as eddy advection, work from BL parameterization, and work from subgrid-scale vertical diffusion throughout the free atmosphere.
The limitation to the RI of the TC was related to the tendency of $\theta_{v}$, which exhibited similar characteristics in the same stage of each cycle (Figure 12). Stage 1 had the largest absolute magnitude of $\theta_{v}$ tendency, which was always positive. In stages 2 and $3, \theta_{v}$ tendency was positive and small or negative; $\theta_{v}$ tendency averaged across the 


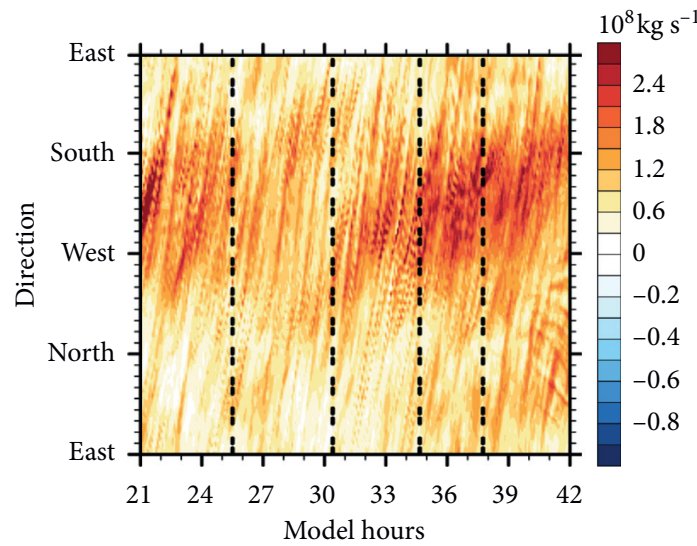

(a)

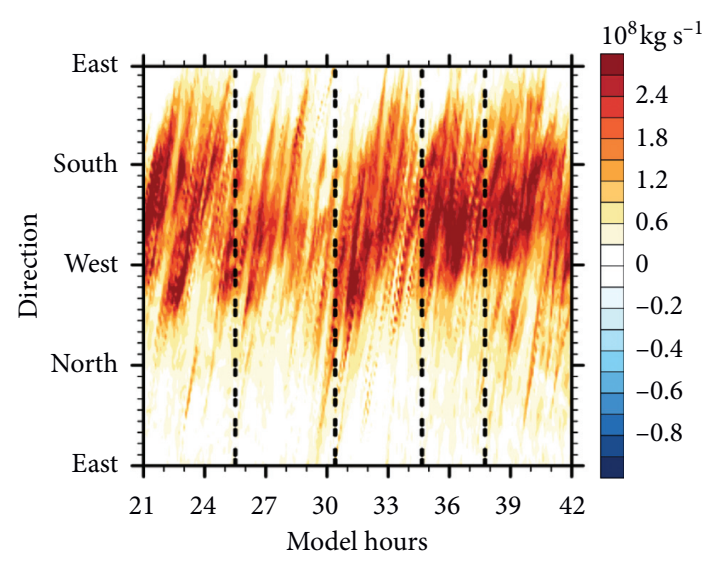

(c)

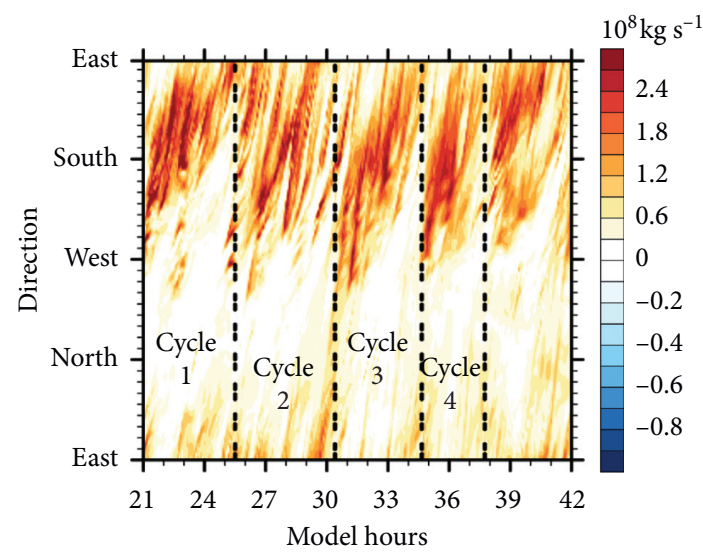

(e)

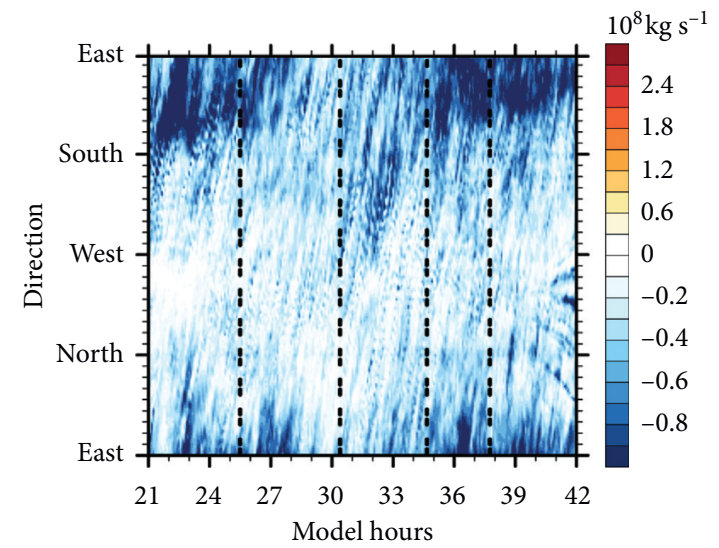

(b)

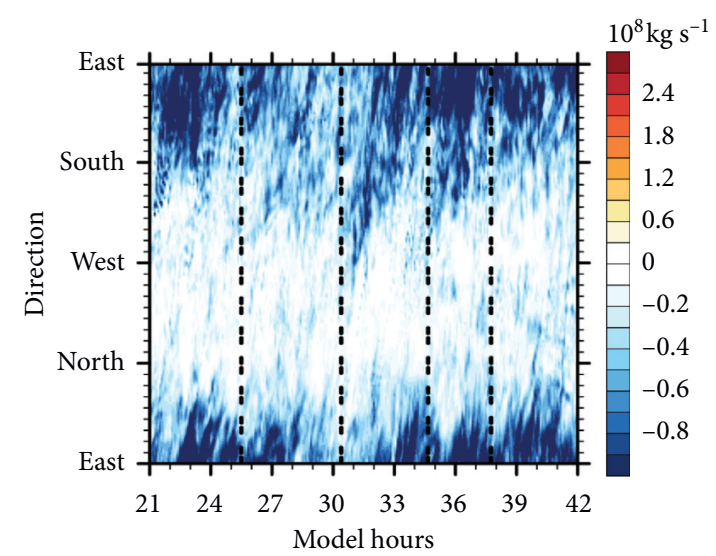

(d)

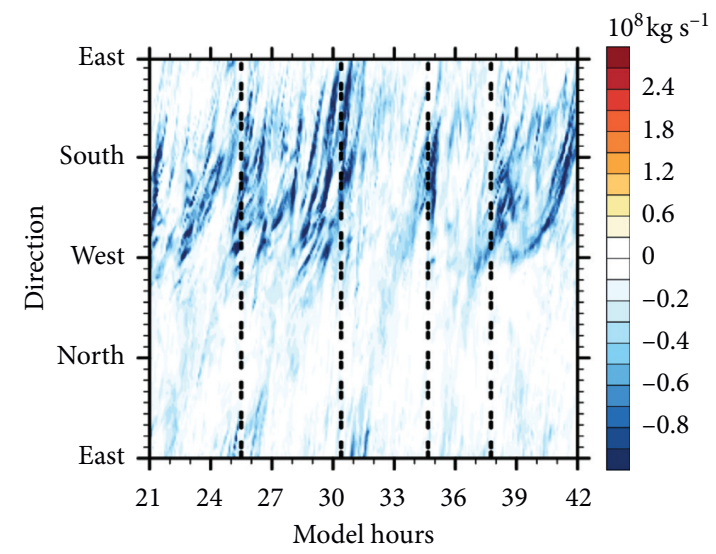

(f)

Figure 10: Time-azimuth diagram of upward mass flux at a radius of 20-80 km at heights of (a) $1.3 \mathrm{~km}$, (c) $5.6 \mathrm{~km}$, and (e) $12.7 \mathrm{~km}$. In each panel, the four periodic cycles are separated by black dashed lines. (b, d, f) They are the same as (a), (c), and (e) but for downward mass flux.

entire layer was approximately 0.44 to $0.64 \mathrm{k} \mathrm{h}^{-1}$ in stage $1,-0.37$ to $-0.03 \mathrm{k} \mathrm{h}^{-1}$ in stage 2 , and -0.33 to $0.02 \mathrm{k} \mathrm{h}^{-1}$ in stage 3 . Although the correspondence between the $\theta_{v}$ tendency and TC intensification during the stages was incomplete, we posit that the reduced IR in stages 2 and 3 might result from the combined inertia of the former stages and the decrease or small increase of $\theta_{v}$, which limited the RI of the TC.
Sensible heat $(\mathrm{SH})$ and $\mathrm{LH}$ from vertical advection were the dominant terms in equation (2). They were the lowest in stage 3, which also had the weakest convection (Figure 11). The cooling caused by the averaged $\mathrm{SH}$ from vertical advection in stage 2 was greater than that in stage 1 by $0.45 \mathrm{kh}^{-1}$. Heating caused by the averaged $\mathrm{LH}$ from vertical advection in stage 2 was less than that in stage 1 by $0.06 \mathrm{kh}^{-1}$. Hence, $\theta_{v}$ decreased in stage 2 because of enhanced cooling caused by $\mathrm{SH}$ from vertical advection and 


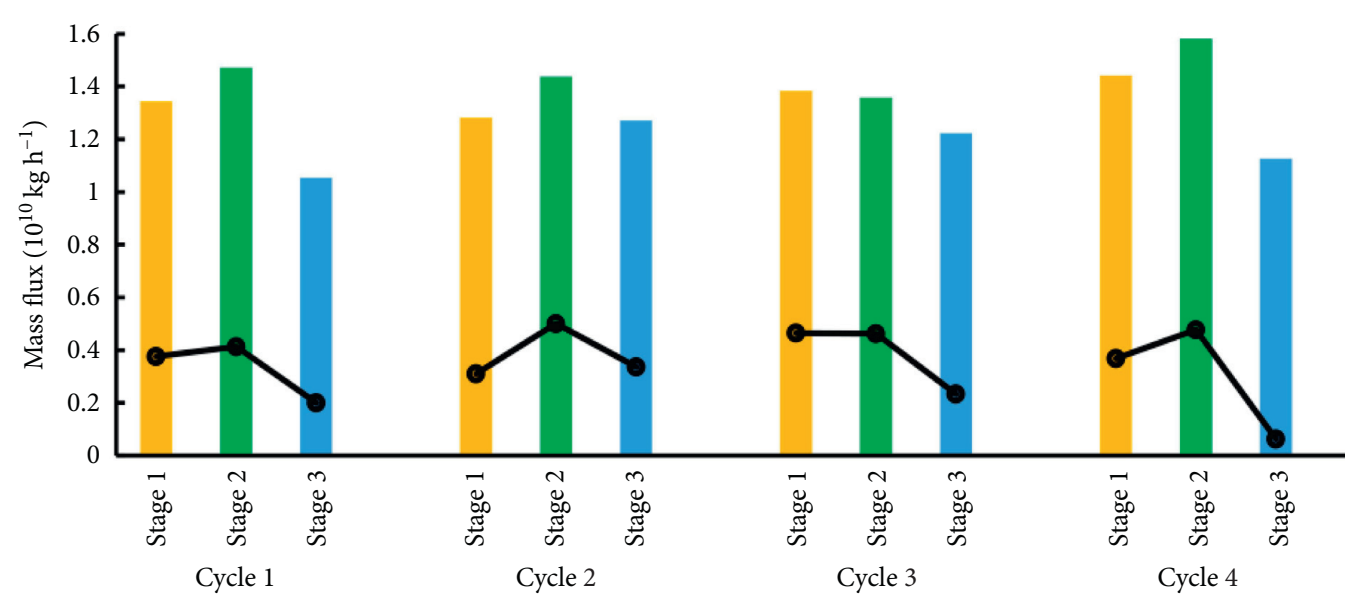

Figure 11: Total mass fluxes at the height of $12.7 \mathrm{~km}$ in the eyewall (bars) and the mass fluxes as a result of $w>7.4 \mathrm{~m} \mathrm{~s}^{-1}$ (lines) for each of the three stages of the four cycles.

weakened heating caused by LH from vertical advection. Eyewall convection in stage 2 was stronger than that in stage 1 , but it had little influence on TC intensification. The distribution of the cooling caused by $\mathrm{SH}$ from vertical advection was consistent with that of convection intensity. Factors underlying the relative magnitudes of $\mathrm{LH}$ from vertical advection in stages 1 and 2 are discussed in Section 3.3. The residual term was relatively large at heights of $4-6 \mathrm{~km}$ and $8-13 \mathrm{~km}$. This might be because the level of detail in the categorization of liquid and solid water was insufficient, and estimates of $\mathrm{LH}$ release were inaccurate. Subgrid-scale diffusion and radiation and nonlinear terms also contributed to the residual term.

The BL parameterization showed a contribution at heights of $<1 \mathrm{~km}$. By separating the horizontal advection $(\mathrm{LH}+\mathrm{SH})$, we found that cooling from the divergence of water vapor $(\mathrm{LH})$ dominated in the $\mathrm{BL}$, while cooling from divergence of $\theta_{v}(\mathrm{SH})$ was less important. Although the air in the BL was converging, when the wind speed and $\theta_{v}$ in the eyewall were larger than those of the periphery, there was a greater exchange with the underlying surface, and the quantity of water vapor in the eyewall was larger than that in the periphery; thus, the horizontal advection caused $\theta_{v}$ to decrease. The LH from vertical advection of $q$ also heated the TC in the BL, and the water vapor used for upward transmission came mainly from the exchange with the underlying surface and the reevaporation of precipitation. However, heating from the convergence of $\theta_{v}(\mathrm{SH})$ and the convergence of water vapor $(\mathrm{LH})$ both occurred at heights of around $6 \mathrm{~km}$ (figures not shown), and water vapor also converged into the eyewall from the periphery.

Figure 13(a) shows the correlation coefficients between $\theta_{v}$ tendency and the contributions of horizontal and vertical advection, $q$ variation, and the residual at different heights. In the $\mathrm{BL}$, the contribution of the local variation of water vapor was negatively correlated with the $\theta_{v}$ tendency, which led to reductions in $\theta_{v}$ as the specific humidity decreased slightly. In contrast, subgrid nonlinear actions could lead to increases in $\theta_{v}$. Under the condition of high temperature and high humidity in the TC center, the positive correlation between horizontal advection and $\theta_{v}$ tendency also caused $\theta_{v}$ to decrease. In the BL, the $\theta_{v}$ tendency was very small (Figure 13(b)). At the heights of around 7 and $13 \mathrm{~km}$, the local variation of $q$ was positively correlated with $\theta_{v}$ tendency, which indicates that increased loss of water vapor after the phase transition corresponded to increased heating of the air. At the tropopause and a height of $11 \mathrm{~km}$, horizontal advection was positively correlated with $\theta_{v}$ tendency, which might be caused by the convergence of inflow that compensated the deep convection in the upper layers and the exchange between the tropopause and the stratosphere. Vertical advection influenced $\theta_{v}$ around the heights of $3-5 \mathrm{~km}$ and above $9 \mathrm{~km}$, where the phase transition of $q$ and the clearest signals of strong convection were present. On average, the highest $\theta_{v}$ tendency was around $4 \mathrm{~km}$ height and in the top layer.

3.3. Discussion. We found periodicity in the IR and $\theta_{v}$ tendency that corresponded with periodic convection in the eyewall, with clear differences between each of the three stages within each cycle. However, convection in stage 2 was stronger than that in stage 1 and caused increases in SH but not in LH. Taking the 95th percentile of the vertical velocity in each layer as the threshold between strong and weak convection, we calculated the updrafts and the downdrafts separately and found that averaged over the four cycles, the LH from strong convection accounted for $29.7 \%$ of total LH. Averaged LH from strong convection in stage 2 was greater than that in stage 1 by $0.08 \mathrm{k} \mathrm{h}^{-1}$. Averaged LH from weak convection in stage 2 was less than that in stage 1 by $0.13 \mathrm{kh}^{-1}$. Figure 14 shows the averaged distribution of the remaining thermodynamic terms of $\mathrm{LH}$ from vertical advection except $w$ (i.e., $-\left(\theta_{v} L_{v, s, f}\right) /\left(C_{p d} T_{v}\right) \cdot \partial$ $q / \partial z$; see equation (2)) with the radius and height of $w$. The differences between the thermodynamic components in different stages were negligible (figures not shown); thus, only the vertical velocity distributions in stages 1 and 2 are shown. As the convection evolved, convection enhancement in stage 2 was greater than that in stage 1, especially at higher altitudes (Figures 14(a) and 14(c)). Updrafts in stage 1 were stronger than those in stage 2 at a radius of $\sim 35 \mathrm{~km}$ in the layers around a height of $6 \mathrm{~km}$. Updrafts in stage 1 were weaker than those in stage 2 above $12 \mathrm{~km}$, which indicates that relative to stage 1 , the convection enhancement in stage 2 was mostly in the area with 


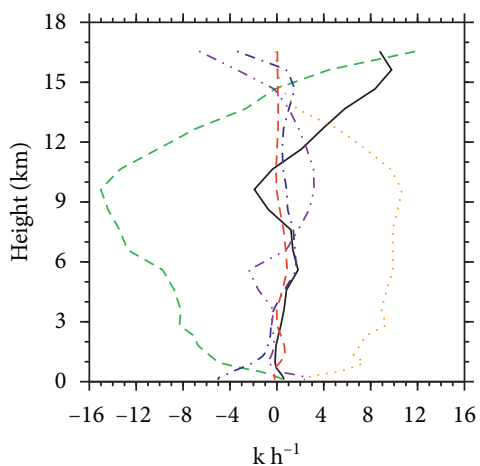

- Potential temperature tendency

. - - - Horizontal advection $(\mathrm{SH}+\mathrm{LH})$

- - - Vertical advection (SH)

Vertical advection ( $\mathrm{LH})$

- - - Local variation of vapor

-... Res.

(a)

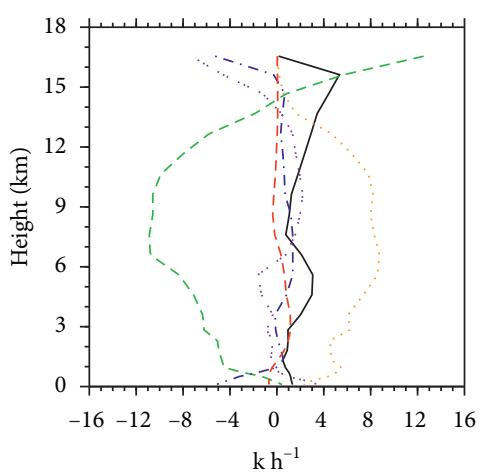

- Potential temperature tendency

. - - Horizontal advection $(\mathrm{SH}+\mathrm{LH})$

- - - Vertical advection (SH)

Vertical advection ( $\mathrm{LH})$

_ - - Local variation of vapor

- - ... Res.

(d)

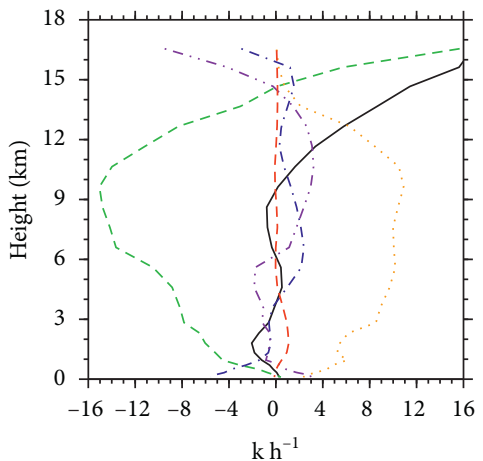

_ Potential temperature tendency

- - - Horizontal advection $(\mathrm{SH}+\mathrm{LH})$

_ - - Vertical advection (SH)

Vertical advection ( $\mathrm{LH}$

- - - Local variation of vapor

- ... Res.

(g)

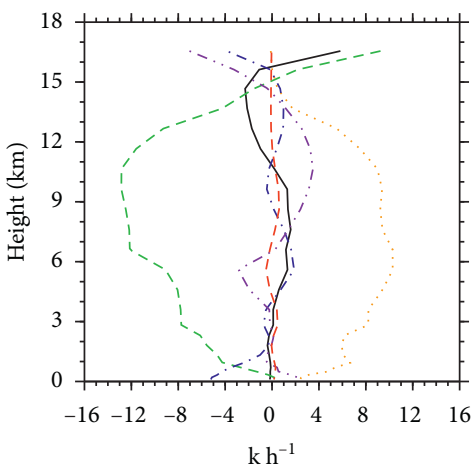

_ Potential temperature tendency

. - - - Horizontal advection $(\mathrm{SH}+\mathrm{LH})$

_ - - Vertical advection (SH)

Vertical advection (LH)

- - - Local variation of vapor Res.

(b)

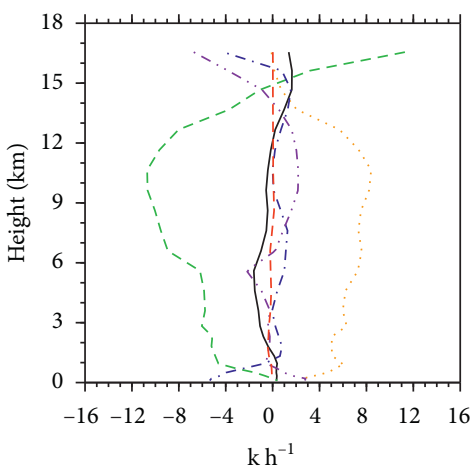

_ Potential temperature tendency

. - - Horizontal advection $(\mathrm{SH}+\mathrm{LH})$

- - - Vertical advection (SH)

Vertical advection (LH)

- - - Local variation of vapor

. - ... Res.

(e)

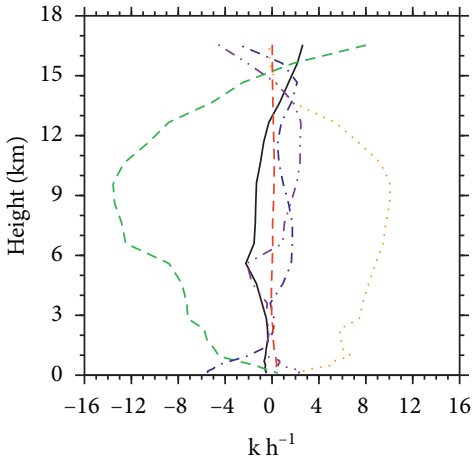

_ Potential temperature tendency

. . - Horizontal advection $(\mathrm{SH}+\mathrm{LH})$

- - - Vertical advection (SH)

Vertical advection ( $\mathrm{LH})$

- - - Local variation of vapor

. - ... Res.

(h)

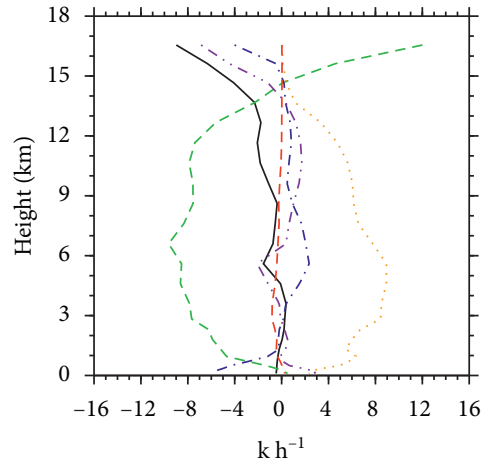

Potential temperature tendency

- . - Horizontal advection $(\mathrm{SH}+\mathrm{LH})$

- - - Vertical advection (SH)

Vertical advection (LH)

- - - Local variation of vapor

-... Res.

(c)

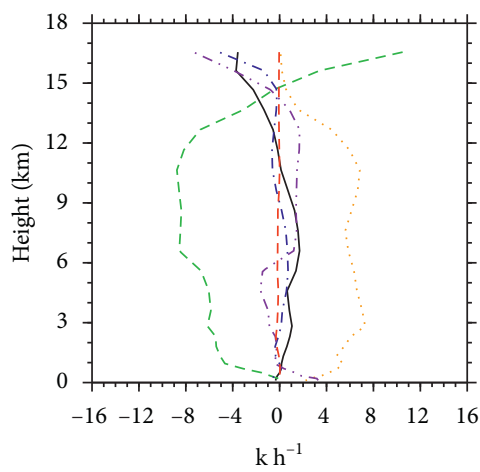

_ Potential temperature tendency

. - - - Horizontal advection $(\mathrm{SH}+\mathrm{LH})$

- - - Vertical advection (SH)

Vertical advection (LH)

- - - Local variation of vapor

- - . Res.

(f)

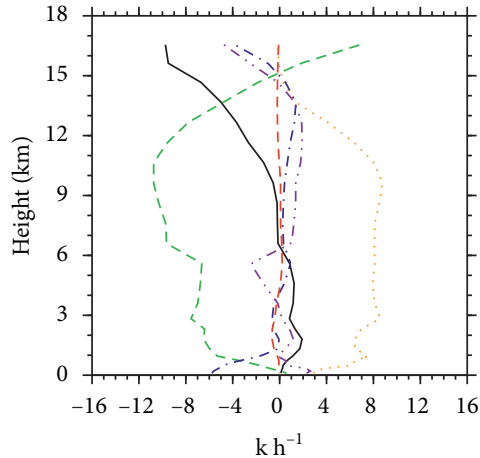

- Potential temperature tendency

-. - Horizontal advection $(\mathrm{SH}+\mathrm{LH})$

- - - Vertical advection (SH)

Vertical advection (LH)

- - - Local variation of vapor

..... Res.

(i)

Figure 12: Continued. 


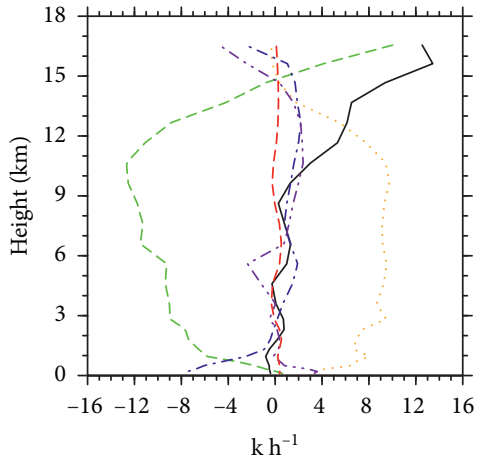

- - - Horizontal advection $(\mathrm{SH}+\mathrm{LH})$

- - - Vertical advection (SH)

Vertical advection (LH)

_ - - Local variation of vapor

-... Res.

(j)

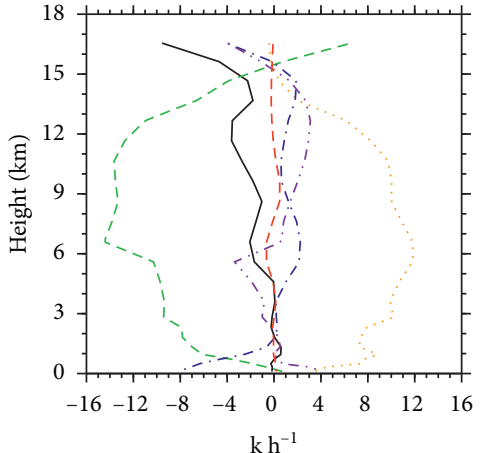

- Potential temperature tendency

- . - Horizontal advection $(\mathrm{SH}+\mathrm{LH})$

- . - Vertical advection (SH)

Vertical advection (LH)

- - - Local variation of vapor

- - ... Res.

(k)

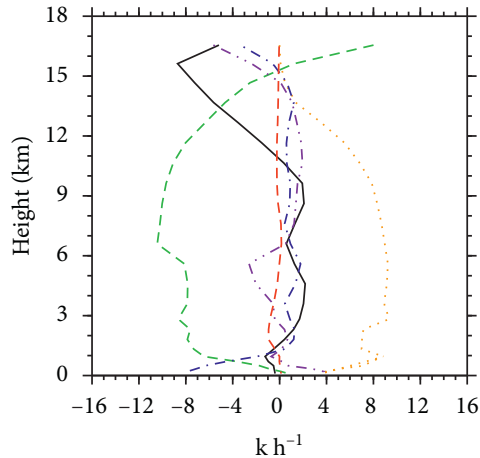

— Potential temperature tendency

- - - Horizontal advection $(\mathrm{SH}+\mathrm{LH})$

- - - Vertical advection (SH)

... Vertical advection (LH)

- - - Local variation of vapor

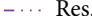

Figure 12: Terms from the diagnosis equation of virtual potential temperature (equation (2)) averaged over a radius of $80 \mathrm{~km}$ (unit: $\mathrm{kh} \mathrm{h}^{-1}$ ). The black line indicates the tendency of virtual potential temperature $\left(\partial \theta_{v} / \partial t\right)$ multiplied by 5 for a clearer display. The green line indicates sensible heat $(\mathrm{SH})$ from vertical advection $\left(-w \cdot \partial \theta_{v} / \partial z\right)$. The blue line indicates latent heat (LH) from horizontal advection $\left(-\left(u \cdot \partial \theta v / r \partial \varphi+\left(\theta_{v} L_{v, s, f}\right) /\left(C_{p d} T_{v}\right) \cdot u \partial q / r \partial \varphi-v \cdot \partial \theta v / \partial r+\left(\theta_{v} L_{v, s, f}\right) /\left(C_{p d} T_{v}\right) \cdot v \partial q / \partial r\right)\right)$. The orange line indicates LH from vertical advection $\left(-\left(\theta_{v} L_{v, s, f}\right) /\left(C_{p d} T_{v}\right) \cdot w \partial q / \partial z\right)$. The red line indicates LH from water vapor tendency $\left.\left(-\left(\theta_{v} L_{v, s, f}\right) /\left(C_{p d} T_{v}\right) \cdot \partial q / \partial t\right)\right)$. The purple line indicates the residual term. (a) Stage 1, cycle 1. (b) Stage 2, cycle 1. (c) Stage 3, cycle 1. (d) Stage 1, cycle 2. (e) Stage 2, cycle 2. (f) Stage 3, cycle 2. (g) Stage 1, cycle 3. (h) Stage 2, cycle 3. (i) Stage 3, cycle 3. (j) Stage 1, cycle 4. (k) Stage 2, cycle 4. (l) Stage 3, cycle 4.

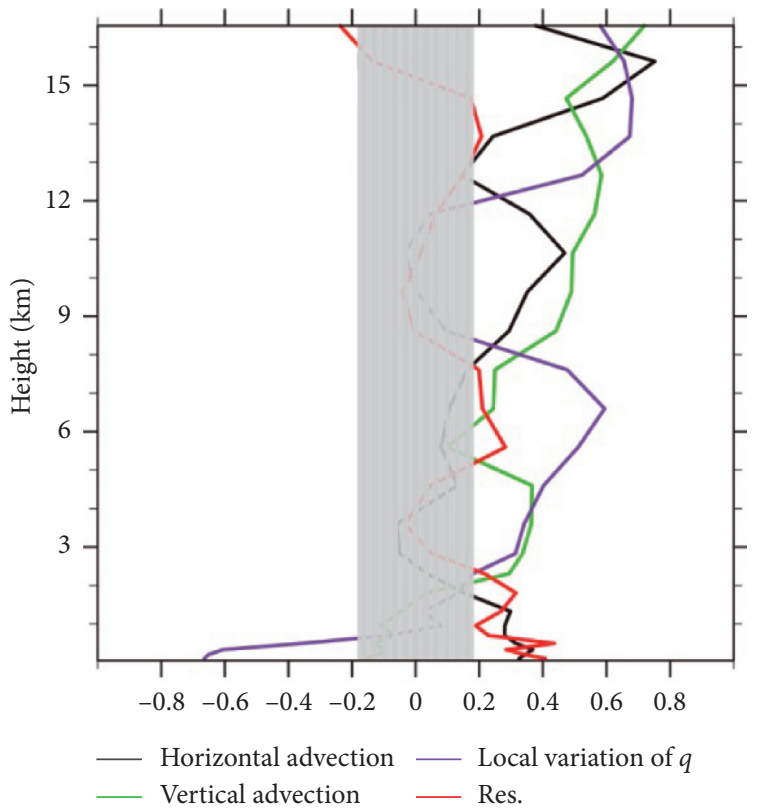

(a)

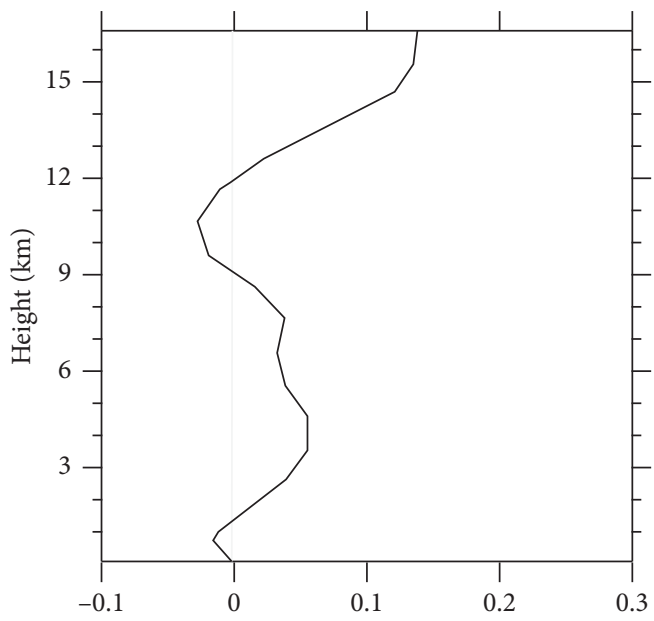

(b)

FIGURE 13: (a) Correlation coefficients between $\theta_{v}$ tendency and the contribution of horizontal advection (including SH and LH; $-\left(u \cdot \partial \theta_{v} / r \partial \varphi+\left(\theta_{v} L_{v, s, f}\right) /\left(C_{p d} T_{v}\right) \cdot u \partial q / r \partial \varphi-\left(v \cdot \partial \theta_{v} / \partial r+\left(\theta_{v} L_{v, s, f}\right) /\left(C_{p d} T_{v}\right) \cdot v \partial q / \partial r\right)\right.$; black), the contribution of vertical advection (including SH and LH; $-w \cdot \partial \theta_{v} / \partial z-\left(\theta_{v} L_{v, s, f}\right) /\left(C_{p d} T_{v}\right) \cdot w \partial q / \partial z$; green), LH from the local variation of $q\left(-\left(\theta_{v} L_{v, s, f}\right) /\left(C_{p d} T_{v}\right) \cdot \partial q / \partial t\right.$; purple), and the residual term (red), calculated using the 200 sets of data of the four cycles. Areas outside the gray mask indicate statistical significance at the $99 \%$ confidence level. (b) Variation of the averaged $\theta_{v}$ tendency with height.

the smaller thermodynamic component (Figure 14(e)). The difference between the distributions of the thermodynamic component of the two stages was smaller under weak convection. The thermodynamic term had the largest value at a radius of $\sim 35 \mathrm{~km}$ in the layers around a height $6 \mathrm{~km}$, which indicates that relative to stage 2 , the convection enhancement in 


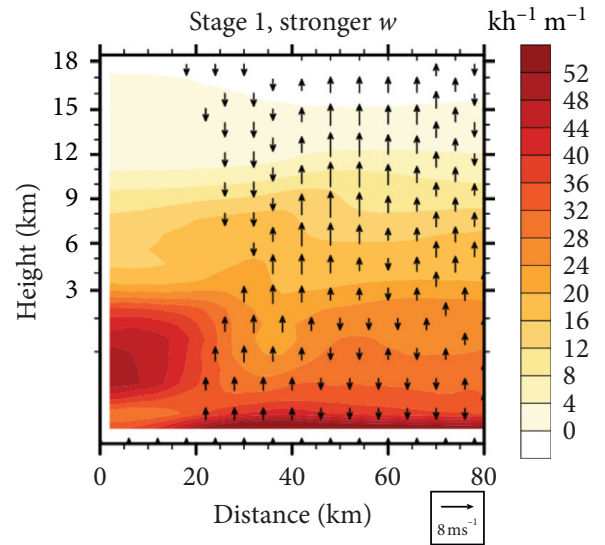

(a)

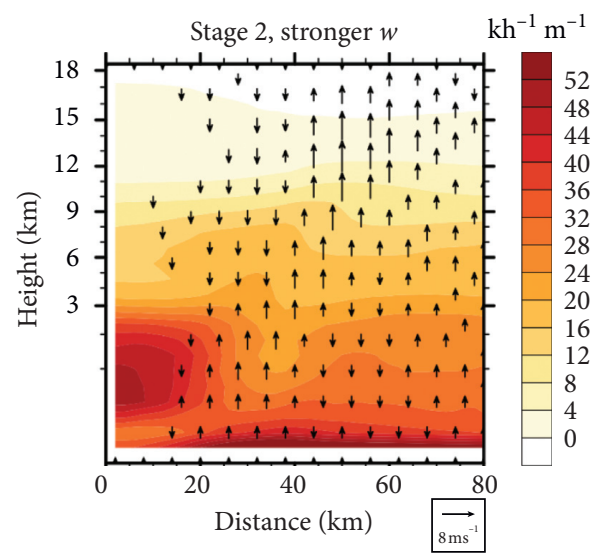

(c)

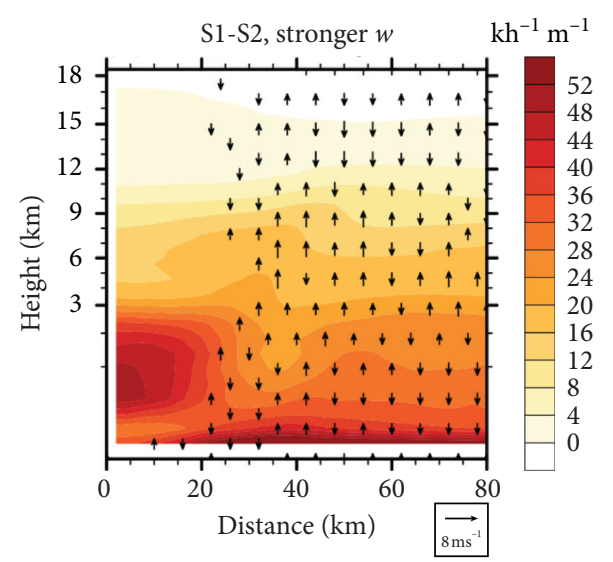

(e)

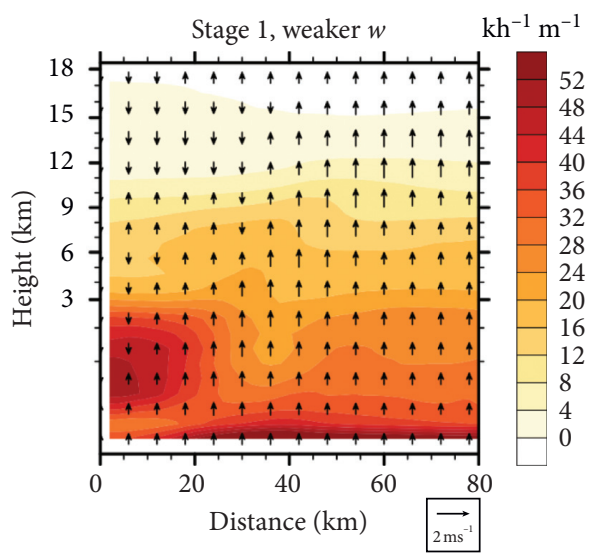

(b)

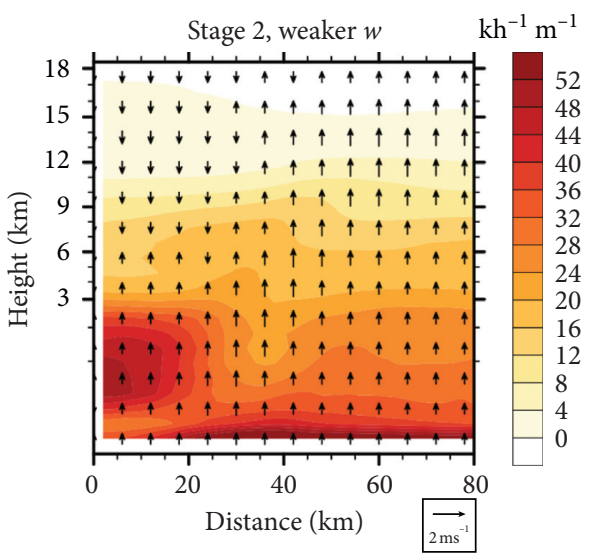

(d)

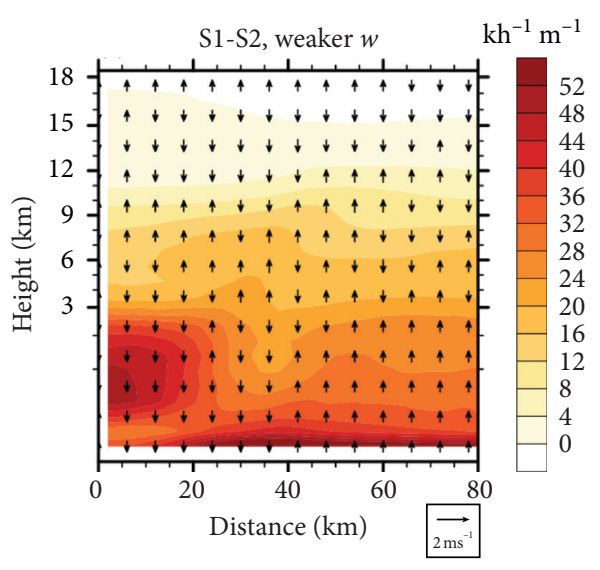

(f)

FIGURE 14: Variation of the azimuthally averaged remaining thermodynamic terms of LH from vertical advection except $w\left(-\left(\theta_{v} L_{v, s, f}\right) /\left(C_{p d}\right.\right.$ $\left.T_{v}\right) \cdot \partial q / \partial z$ in equation (2); shading) with the radius and height of $w$ (vectors). (a, c, e) The velocities with absolute values above the threshold defined in Section 3.3. (b, d, f) The velocities with absolute values below the threshold.

stage 1 was mostly in the area with the larger thermodynamic component. Hence, unlike the increase in SH cooling, the overall increase in LH heating from vertical advection in stage 2 was small possibly because of changes in the relationship between the convection evolution and the distribution of the environmental thermal field. For detailed analysis and identification of the mechanisms involved, additional case studies based on observations and numerical experiments are needed.
The transitions between different cycles and stages are interesting. Because these periodic features were mainly transported vertically from the BL (i.e., Figure 10), we further analyzed the periodicity in horizontal divergence at a height of $0.95 \mathrm{~km}$, which indicated the periodicity in the evolution of convection in the BL (Figure 15). During each stage, there was a convergence feature with a period of $\sim 1 \mathrm{~h}$ in the southwest direction, possibly related to single cells of strong convection. 


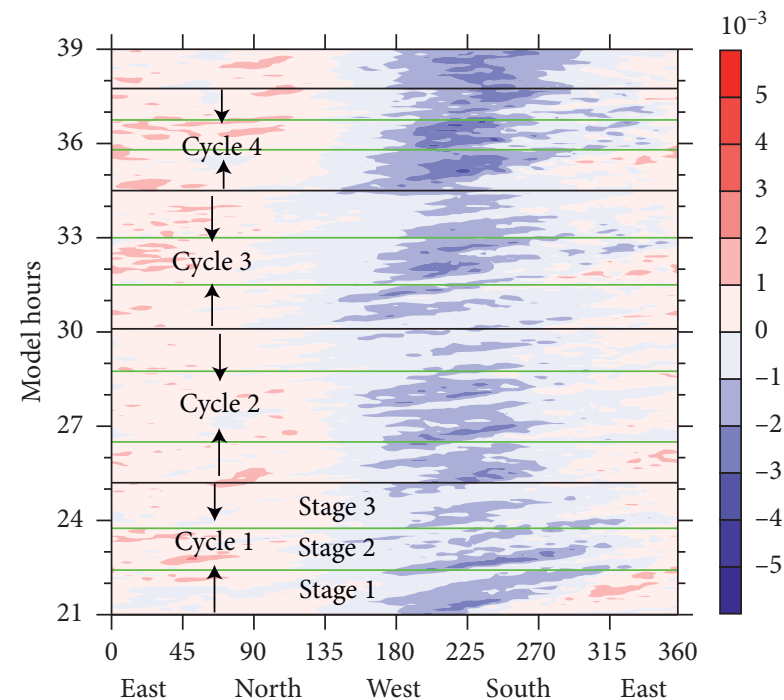

FIGURE 15: Variation of horizontal divergence at the height of $0.95 \mathrm{~km}$ with model hours and azimuth. The black lines identify different cycles, and the green lines identify different stages.

The merging of strong convection in each of the three stages possibly contributes to the period of $3-5 \mathrm{~h}$ for each cycle. Based on previous studies (i.e., [25, 28-31]), the transition of different stages/cycles of strong convection might be related to the distribution of vertical wind shear and the TC's rotation, accompanied by the interaction between VRWs and convection. Density oscillations in the $\mathrm{BL}$ also contribute towards this phenomenon. Further comprehensive studies are needed to identify the dynamics and thermodynamic processes related to the vertical structure and organization of the eyewall and eyewall weakening during the transition from stage 2 to stage 3 , as well as eyewall reconstruction during the transition from stage 3 to stage 1 of the following cycle.

\section{Summary and Conclusions}

Tropical cyclones are among the most destructive natural phenomena, and they often cause numerous casualties and heavy financial losses. The ability to forecast TC intensity has improved modestly in recent years, partly because of inadequate understanding of the internal processes of TCs. The periodic activities of the eyewall are important internal processes that affect TC intensity. However, previous studies have generally focused on the long-term evolution of the eyewall and changes in TC intensity, whereas few studies have considered the shortterm periodic activities and vertical propagation of the eyewall related to TC intensification. Thus, in this study, we analyzed the periodic cycles of convection in the eyewall and investigated their influence on TC intensification using radar observations and a numerical simulation of Typhoon Hato (2017).

We analyzed radar composite reflectivity from the operational weather radar network in Guangdong Province and a concatenation of radar echo images from Zhuhai and Hong Kong to examine the evolution of the short-term periodic activities in eyewall convection during the RI of the TC. We identified nearly two complete cycles (period: approximately $\geq 3 \mathrm{~h}$ ) during the period of approximately $6 \mathrm{~h}$ before Hato made landfall. In each cycle, weak convection within the eyewall intensified, rotated counterclockwise, reached maximum intensity, and then weakened gradually until the entire eyewall was filled and the convective structure was relatively uniform.

Our analysis was primarily based on a WRF-ARW simulation of Hato because the radar observations were unable to capture eyewall convection when the TC was far from the southern coast of China. We compared simulation results with observations and concluded that the model successfully reproduced the track, intensity, and precipitation structure of Hato. The periodic cycles in the eyewall convection were also reproduced satisfactorily in the simulation during model hours $31-38$. We analyzed the stage with a relatively steady IR (model hours 21-39) to determine the effects of the short-term periodic activities of eyewall convection on TC intensification.

The simulation showed that convection of the eyewall of Hato exhibited periodic cycles with a period of $3-5 \mathrm{~h}$, which limited the RI of Hato. During each cycle, severe vertical motions and mass fluxes rotated counterclockwise. As eyewall convection evolved through different stages in each cycle, the stability of the TC IR varied. Results from the $\theta_{v}$ diagnosis equation showed that the $\theta_{v}$ tendency exhibited similar characteristics in the same stage of different cycles. Stage 1 had the largest absolute magnitude of $\theta_{v}$ tendency, which was always positive. In stages 2 and $3, \theta_{v}$ tendency was positive and small or negative. In relation to the $\theta_{v}$ tendency, $\mathrm{SH}$ and $\mathrm{LH}$ from vertical advection were the dominant terms. The structure of the eyewall controlled heating generated by these two processes. In stage 1 , the large amount of heat released by the vertical transport of LH was not fully compensated by other processes, resulting in a maximum IR. In stage 2 , IR was smaller. This is the result of reduction in latent heating from the vertical advection and a considerable increase in sensible cooling from the vertical advection, which can be attributed to the shift between the eyewall convection and the environmental thermal field and the increase in the vertical mass fluxes, respectively. In stage 3, heating was reduced because vertical transport was at its weakest. Hence, IR in stage 3 was the smallest, which limited the RI of the TC. The periodic eyewall convection activities controlled the short-term evolution of the IR of the TC and stopped the TC from continuing to intensify and develop an extreme IR. These findings can be useful for short-term TC intensity forecast.

\section{Data Availability}

The WRF source code is freely available from the WRF user page (http://www2.mmm.ucar.edu/wrf/users/). The initial and boundary conditions of the WRF model can be obtained from the medium-range forecasts produced by the Regional Specialized Meteorological Centre of the European Centre for Medium-Range Weather Forecasts (https://www.ecmwf.int/). The JTWC best-track data are available at https://www.metoc. navy.mil/jtwc/jtwc.html?best-tracks. The JMA best-track data are available at http://www.jma.go.jp/jma/jma-eng/jma-center/ rsmc-hp-pub-eg/besttrack.html. The radar composite reflectivity data from the CMA are available at http://data.cma.cn/. 
The CMA best-track data are available at http://tcdata.typhoon. org.cn/zjljsjj_zlhq.html.

\section{Conflicts of Interest}

The authors declare that there are no conflicts of interest regarding the publication of this paper.

\section{Acknowledgments}

The authors wish to thank the Guangzhou Institute of Tropical and Marine Meteorology and Zhuhai National Climate Observatory for providing the radar observation data. The authors would like to thank Editage (https://www. editage.cn) and Tina Tin, PhD, and Leonie Seabrook, PhD, from Liwen Bianji (Edanz) (https://www.liwenbianji.cn) for editing the language of the draft of this manuscript. This work was supported by the Special Program for Key Research and Development of Guangdong Province (Grant no. 2019B111101002), Guangzhou Science and Technology Plan Project (201903010036), and the National Natural Science Foundation of China (41675043 and 42075004).

\section{References}

[1] M. DeMaria, C. R. Sampson, J. A. Knaff et al., "Is tropical cyclone intensity guidance improving?" Bulletin of the American Meteorological Society, vol. 95, pp. 387-398, 2012.

[2] K. Emanuel and F. Zhang, "On the predictability and error sources of tropical cyclone intensity forecasts," Journal of the Atmospheric Sciences, vol. 73, no. 9, pp. 3739-3747, 2016.

[3] R. Rios-Berrios, T. Vukicevic, and B. Tang, "Adopting model uncertainties for tropical cyclone intensity prediction," Monthly Weather Review, vol. 142, no. 1, pp. 72-78, 2014.

[4] E. A. Hendricks, "Internal dynamical control on tropical cyclone intensity variability-a review," Tropical Cyclone Research and Review, vol. 1, pp. 72-78, 2012.

[5] A. Khain, B. Lynn, and J. Shpund, "High resolution WRF simulations of hurricane Irene: sensitivity to aerosols and choice of microphysical schemes," Atmospheric Research, vol. 167, pp. 129-145, 2016.

[6] M. D. Leroux, K. Wood, R. Elsberry et al., "Recent advances in research and forecasting of tropical cyclone track, intensity, and structure at landfall," Tropical Cyclone Research and Review, vol. 7, pp. 85-105, 2018.

[7] X. Qin and M. Mu, "Can adaptive observations improve tropical cyclone intensity forecasts?" Advances in Atmospheric Sciences, vol. 31, no. 2, pp. 252-262, 2014.

[8] X. Y. Zhuge, J. Guan, F. Yu et al., "A new satellite-based indicator for estimation of the western north pacific tropical cyclone current intensity," IEEE Transactions on Geoscience and Remote Sensing, vol. 53, pp. 5661-5676, 2015.

[9] G. Paull, K. Menelaou, and M. K. Yau, "Sensitivity of tropical cyclone intensification to axisymmetric heat sources: the role of inertial stability," Journal of the Atmospheric Sciences, vol. 74, no. 7, pp. 2325-2340, 2017.

[10] C.-C. Wu, S.-N. Wu, H.-H. Wei, and S. F. Abarca, "The role of convective heating in tropical cyclone eyewall ring evolution," Journal of the Atmospheric Sciences, vol. 73, no. 1, pp. 319-330, 2015.

[11] D. S. Nolan, Y. Moon, and D. P. Stern, "Tropical cyclone intensification from asymmetric convection: energetics and efficiency," Journal of the Atmospheric Sciences, vol. 64, no. 10, pp. 3377-3405, 2007.

[12] L. J. Shapiro and H. E. Willoughby, "The response of balanced hurricanes to local sources of heat and momentum," Journal of the Atmospheric Sciences, vol. 39, no. 2, pp. 378-394, 1982.

[13] R. K. Smith and M. T. Montgomery, "The efficiency of diabatic heating and tropical cyclone intensification," Quarterly Journal of the Royal Meteorological Society, vol. 142, no. 698, pp. 2081-2086, 2016.

[14] J. L. Vigh and W. H. Schubert, "Rapid development of the tropical cyclone warm core," Journal of the Atmospheric Sciences, vol. 66, no. 11, pp. 3335-3350, 2009.

[15] R. Rogers, P. Reasor, and S. Lorsolo, “Airborne Doppler observations of the inner-core structural differences between intensifying and steady-state tropical cyclones," Monthly Weather Review, vol. 141, no. 9, pp. 2970-2991, 2013.

[16] S. D. Aberson, J. A. Zhang, and K. N. Ocasio, "An extreme event in the eyewall of hurricane Felix on 2 September 2007," Monthly Weather Review, vol. 145, no. 6, pp. 2083-2092, 2017.

[17] A. M. Foerster, M. M. Bell, P. A. Harr, and S. C. Jones, "Observations of the eyewall structure of typhoon Sinlaku (2008) during the transformation stage of extratropical transition," Monthly Weather Review, vol. 142, no. 9, pp. 3372-3392, 2014.

[18] A. T. Hazelton, R. F. Rogers, and R. E. Hart, "Analyzing simulated convective bursts in two Atlantic hurricanes. Part I: burst formation and development," Monthly Weather Review, vol. 145, no. 8, pp. 3073-3094, 2017.

[19] X.-Y. Zhuge, J. Ming, and Y. Wang, "Reassessing the use of inner-core hot towers to predict tropical cyclone rapid intensification," Weather and Forecasting, vol. 30, no. 5, pp. 1265-1279, 2015.

[20] R. Rogers, "Convective-scale structure and evolution during a high-resolution simulation of tropical cyclone rapid intensification," Journal of the Atmospheric Sciences, vol. 67, no. 1, pp. 44-70, 2010.

[21] X. Tang, F. Ping, S. Yang, M. Li, and J. Peng, "Relationship between convective bursts and the rapid intensification of Typhoon Mujigae (2015)," Atmospheric Science Letters, vol. 19, no. 4, Article ID e811, 2018.

[22] P. M. Finocchio, S. J. Majumdar, D. S. Nolan, and M. Iskandarani, "Idealized tropical cyclone responses to the height and depth of environmental vertical wind shear," Monthly Weather Review, vol. 144, no. 6, pp. 2155-2175, 2016.

[23] Q. H. Li, H. C. Lu, W. Zhong et al., "Influence of bimodel vertical wind shear on typhoon structure and intensity," Chinese Journal of Geophysics- Chinese Edition, vol. 59, pp. 587-604, 2016.

[24] B. Tang and K. Emanuel, "Sensitivity of tropical cyclone intensity to ventilation in an axisymmetric model," Journal of the Atmospheric Sciences, vol. 69, no. 8, pp. 2394-2413, 2012.

[25] J. P. Kossin, "Daily hurricane variability inferred from GOES infrared imagery," Monthly Weather Review, vol. 130, no. 9, pp. 2260-2270, 2002.

[26] M. D. Leroux, M. Plu, and F. Roux, "On the sensitivity of tropical cyclone intensification under upper-level trough forcing," Monthly Weather Review, vol. 144, pp. 1179-1202, 2014.

[27] P. D. Reasor, M. D. Eastin, and J. F. Gamache, "Rapidly intensifying hurricane Guillermo (1997). Part I: lowwavenumber structure and evolution," Monthly Weather Review, vol. 137, no. 2, pp. 603-631, 2009. 
[28] T. Itano and M. Hosoya, "Spectral analyses of the polygonal eye of typhoon Sinlaku," Monthly Weather Review, vol. 141, no. 3, pp. 987-996, 2013.

[29] K. Menelaou and M. K. Yau, "On the role of asymmetric convective bursts to the problem of hurricane intensification: radiation of vortex rossby waves and wave-mean flow interactions," Journal of the Atmospheric Sciences, vol. 71, no. 6, pp. 2057-2077, 2014.

[30] M. T. Montgomery and R. J. Kallenbach, "A theory for vortex rossby-waves and its application to spiral bands and intensity changes in hurricanes," Quarterly Journal of the Royal Meteorological Society, vol. 123, no. 538, pp. 435-465, 1997.

[31] D. A. Schecter, "The spontaneous imbalance of an atmospheric vortex at high rossby number," Journal of the Atmospheric Sciences, vol. 65, no. 8, pp. 2498-2521, 2008.

[32] H.-C. Kuo, R. T. Williams, and J.-H. Chen, "A possible mechanism for the eye rotation of typhoon Herb," Journal of the Atmospheric Sciences, vol. 56, no. 11, pp. 1659-1673, 1999.

[33] P. D. Reasor, "Horizontal vorticity redistribution and vortex alignment in developing and mature tropical cyclones," Doctor of Philosophy, Colorado State University, Fort Collins, Colorado, 2000.

[34] H. C. Kuo, W. Y. Cheng, Y. T. Yang et al., "Deep convection in elliptical and polygonal eyewalls of tropical cyclones," Journal of Geophysical Research-Atmospheres, vol. 121, pp. 14456-14468, 2016.

[35] S. Chen, Y. Lu, W. Li, and Z. Wen, "Identification and analysis of high-frequency oscillations in the eyewalls of tropical cyclones," Advances in Atmospheric Sciences, vol. 32, no. 5, pp. 624-634, 2015.

[36] K. A. Emanuel, "An air-sea interaction theory for tropical cyclones. Part I: steady-state maintenance," Journal of the Atmospheric Sciences, vol. 43, no. 6, pp. 585-605, 1986.

[37] S. R. Guimond, G. M. Heymsfield, P. D. Reasor, and A. C. Didlake, "The rapid intensification of hurricane Karl (2010): new remote sensing observations of convective bursts from the global hawk platform," Journal of the Atmospheric Sciences, vol. 73, no. 9, pp. 3617-3639, 2016.

[38] D. P. Stern and D. S. Nolan, "On the height of the warm core in tropical cyclones," Journal of the Atmospheric Sciences, vol. 69, no. 5, pp. 1657-1680, 2012.

[39] S. Chen, W. Li, Z. Wen et al., "Variations in high-frequency oscillations of tropical cyclones over the western north pacific," Advances in Atmospheric Sciences, vol. 35, no. 4, pp. 423-434, 2018.

[40] M. Ying, W. Zhang, H. Yu et al., "An overview of the China meteorological administration tropical cyclone database," Journal of Atmospheric and Oceanic Technology, vol. 31, no. 2, pp. 287-301, 2014.

[41] X. Chen, Y. Wang, K. Zhao, and D. Wu, "A numerical study on rapid intensification of typhoon Vicente (2012) in the south China sea. Part I: verification of simulation, storm-scale evolution, and environmental contribution," Monthly Weather Review, vol. 145, no. 3, pp. 877-898, 2017.

[42] T. Islam, P. K. Srivastava, M. A. Rico-Ramirez, Q. Dai, M. Gupta, and S. K. Singh, "Tracking a tropical cyclone through WRF-ARW simulation and sensitivity of model physics," Natural Hazards, vol. 76, no. 3, pp. 1473-1495, 2015.

[43] E. J. Mlawer, S. J. Taubman, P. D. Brown et al., "Radiative transfer for inhomogeneous atmospheres: RRTM, a validated correlated-k model for the longwave," Journal of Geophysical Research: Atmospheres, vol. 102, pp. 16663-16682, 1997.

[44] J. Dudhia, "Numerical study of convection observed during the winter monsoon experiment using a mesoscale two- dimensional model," Journal of the Atmospheric Sciences, vol. 46, no. 20, pp. 3077-3107, 1989.

[45] D. Zhang and R. A. Anthes, "A high-resolution model of the planetary boundary layer-sensitivity tests and comparisons with SESAME-79 data," Journal of Applied Meteorology, vol. 21, no. 11, pp. 1594-1609, 1982.

[46] M. Ek, K. Mitchell, Y. Lin et al., "Implementation of Noah land surface model advances in the National Centers for Environmental Prediction operational mesoscale Eta model," Journal of Geophysical Research-Atmospheres, vol. 108, no. d22, pp. 129-151, 2003.

[47] S. Hong, Y. Noh, and J. Dudhia, "Nonlocal boundary layer vertical diffusion in a medium-range forecast model," Monthly Weather Review, vol. 124, no. 1, pp. 2322-2339, 2006.

[48] S. Y. Hong and J. O. J. Lim, "The WRF single-moment 6-class microphysics scheme (WSM6)," Journal of the Korean Meteorological Society, vol. 42, pp. 129-131, 2006.

[49] J. S. Kain and J. M. Fritsch, "A one-dimensional entraining/ detraining plume model and its application in convective parameterization," Journal of the Atmospheric Sciences, vol. 47, no. 23, pp. 2784-2802, 1990.

[50] J. M. Kain, "Convective parameterization for mesoscale models: the Kain-Fritsch scheme," The Representation of Cumulus Convection in Numerical Models, vol. 24, pp. 165170, 1993.

[51] J. S. Kain, "The Kain-fritsch convective parameterization: an update," Journal of Applied Meteorology, vol. 43, no. 1, pp. 170-181, 2004.

[52] C. R. Holliday and A. H. Thompson, "Climatological characteristics of rapidly intensifying typhoons," Monthly Weather Review, vol. 107, no. 8, pp. 1022-1034, 1979.

[53] S. Kanada and A. Wada, "Numerical study on the extremely rapid intensification of an intense tropical cyclone: typhoon Ida (1958)," Journal of the Atmospheric Sciences, vol. 72, no. 11, pp. 4194-4217, 2015.

[54] A. Grinsted, J. C. Moore, and S. Jevrejeva, "Application of the cross wavelet transform and wavelet coherence to geophysical time series," Nonlinear Processes in Geophysics, vol. 11, no. 5/6, pp. 561-566, 2004.

[55] Y. Liu, D.-L. Zhang, and M. K. Yau, “A multiscale numerical study of hurricane Andrew (1992). Part II: kinematics and inner-core structures," Monthly Weather Review, vol. 127, no. 11, pp. 2597-2616, 1999.

[56] M. L. Black, J. F. Gamache, F. D. Marks Jr., C. E. Samsury, and H. E. Willoughby, "Eastern pacific hurricanes Jimena of 1991 and Olivia of 1994: the effect of vertical shear on structure and intensity," Monthly Weather Review, vol. 130, no. 9, pp. 2291-2312, 2002. 